\title{
Inorganic Nanomaterial for Biomedical Imaging of Brain Diseases
}

\author{
Wenxian Du ${ }^{1}$, Lingling Zhou ${ }^{1}$, Qiang Zhang ${ }^{1}$, Xin Liu ${ }^{2}$, Xiaoer Wei ${ }^{1, *}$ and Yuehua Li ${ }^{1, * \mathbb{D}}$ \\ 1 Department of Radiology, Shanghai Jiao Tong University Affiliated Sixth People's Hospital, \\ Shanghai 200233, China; wx0910@mail.ustc.edu.cn (W.D.); llzhou_joyan@163.com (L.Z.); \\ zhangqiang@shanghaitech.edu.cn (Q.Z.) \\ 2 State Key Laboratory of Bioelectronics, Jiangsu Key Laboratory for Biomaterials and Devices, \\ School of Biological Science \& Medical Engineering, Southeast University, Nanjing 210096, China; \\ liuxin4552@seu.edu.cn \\ * Correspondence: weixiaoer_2003@163.com (X.W.); liyuehua77@sjtu.edu.cn (Y.L.)
}

check for updates

Citation: Du, W.; Zhou, L.; Zhang, Q.; Liu, X.; Wei, X.; Li, Y. Inorganic Nanomaterial for Biomedical Imaging of Brain Diseases. Molecules 2021, 26, 7340. https://doi.org/10.3390/ molecules 26237340

Academic Editors: Weifeng Lin, Linyi Zhu and Jessica Rosenholm

Received: 4 August 2021

Accepted: 5 October 2021

Published: 3 December 2021

Publisher's Note: MDPI stays neutral with regard to jurisdictional claims in published maps and institutional affiliations.

Copyright: (c) 2021 by the authors. Licensee MDPI, Basel, Switzerland. This article is an open access article distributed under the terms and conditions of the Creative Commons Attribution (CC BY) license (https:// creativecommons.org/licenses/by/ $4.0 /)$.

\begin{abstract}
In the past few decades, brain diseases have taken a heavy toll on human health and social systems. Magnetic resonance imaging (MRI), photoacoustic imaging (PA), computed tomography $(\mathrm{CT})$, and other imaging modes play important roles in disease prevention and treatment. However the disadvantages of traditional imaging mode, such as long imaging time and large noise, limit the effective diagnosis of diseases, and reduce the precision treatment of diseases. The ever-growing applications of inorganic nanomaterials in biomedicine provide an exciting way to develop novel imaging systems. Moreover, these nanomaterials with special physicochemical characteristics can be modified by surface modification or combined with functional materials to improve targeting in different diseases of the brain to achieve accurate imaging of disease regions. This article reviews the potential applications of different types of inorganic nanomaterials in vivo imaging and in vitro detection of different brain disease models in recent years. In addition, the future trends, opportunities, and disadvantages of inorganic nanomaterials in the application of brain diseases are also discussed. Additionally, recommendations for improving the sensitivity and accuracy of inorganic nanomaterials in screening/diagnosis of brain diseases.
\end{abstract}

Keywords: biomedical imaging; inorganic nanomaterial; brain disease

\section{Introduction}

The rising incidence of brain diseases over the past few years has become the most common cause of disability and death worldwide, placing a heavy burden on families and societies. Brain diseases can be divided into many types. The first category is tumors of the brain, including primary tumors of the brain, such as gliomas. It also includes brain metastases from secondary brain tumors, such as lung, breast, prostate, and colorectal cancer [1]. The second category is brain trauma, such as concussion, brain contusion and laceration, diffuse axonal injury, various types of intracerebral hemorrhage, and intracranial hemorrhage. The third category is the brain vascular diseases, including ischemic cerebrovascular disease and cerebral aneurysm, hypertensive intracerebral hemorrhage, stroke, and other diseases. In addition, the neurodegenerative diseases caused by the loss of neurons and their myelin sheath, which deteriorate over time and result in dysfunction, are also problematic. For instance, Alzheimer's disease (AD), Parkinson's disease (PD), and epilepsy. To some extent, the central nervous system (CNS) or peripheral nervous system (PNS) is irreversibly damaged by these diseases. Therefore, accurate diagnosis and clinical evaluation of these diseases are very important. However, the current diagnosis method is relatively simple, the resolution is not high, and it is difficult to accurately locate the lesion site, which greatly limits the precise treatment of the disease. So this review introduces different brain diseases and corresponding treatment methods. Then use traditional imaging methods to introduce the imaging applications of inorganic nanomaterials in different 
brain disease models, hoping to inspire more convenient and accurate imaging methods and integration of diagnosis and treatment (Scheme 1).

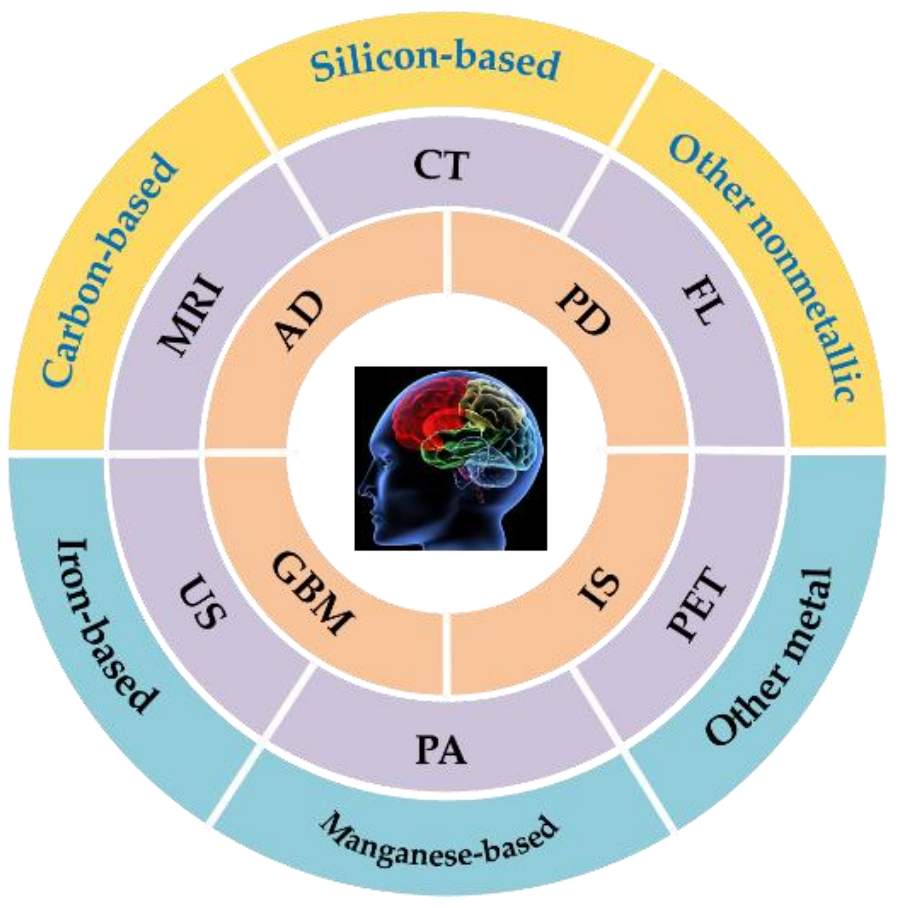

Scheme 1. Different brain diseases with different traditional imaging technologies and the imaging applications of inorganic nanomaterials.

\subsection{Brain Disease}

\subsubsection{Alzheimer's Disease (AD)}

According to the World Health Organisation (WHO) reports that more than 36 million people are suffering from $\mathrm{AD}$. The main pathological features of $\mathrm{AD}$ are amyloid $\beta$ deposition in Senile Plaques (SP) and neurofibrillary tangles (NFTs). The early stage of AD is characterized by memory impairment to a certain extent, and other cognitive impairments (Such as memory loss, aphasia, loss of cognitive ability, and visual space disorders) may occur with the progression of $\mathrm{AD}[2,3]$. The pathogenesis of $\mathrm{AD}$ is very complex, and it is difficult to achieve an early diagnosis of the disease. No specific drug for AD has been developed so far, despite the involvement of interdisciplinary researchers. Therefore, how to maintain and improve the cognitive function of the elderly and improve their quality of life in old age has become a hot issue of scientists.

Targeting the central nervous system is the primary treatment for AD. However, the protective and selective role of the blood-brain barrier (BBB) in the central nervous system prevents the drug from effectively passing through the BBB, thus compromising its efficacy [4]. Zhang et al. developed a dual-functional nanoparticle drug delivery system based on a PEGylated poly (lactic acid) (PLA) polymer. They used phage to filtrate two targeting peptides called TGN and QSH that specifically target ligands at the BBB and affinity with $A \beta_{1-42}$. These two targeting peptides could be conjugated to the surface of the nanoparticles to enhance and target delivery to amyloid plaque in the brains of $\mathrm{AD}$ model mice (Figure 1a) [5]. In another report, Qu's group designed an oligomer-specific fluorescent probe based on the hydrophobic regions that are exposed on the $A \beta$ oligomer surfaces, opening a new door to developing a "sense and treat" system for AD therapy. The probe and KLVFF peptide (an A $\beta$-target peptide) was modified on the surfaces of magnetic nanoparticles (MNP@NFP-pep) to enhance the ability to pass through BBB and recognize $A \beta$ oligomers. Importantly, this complex can detect the $A \beta$ oligomer specifically and realize the wireless deep magnetothermally mediated depolymerization of $A \beta$ oligomer in an alternating magnetic field [6]. Combining nanomedicine with neurodegeneration, 
as shown in Figure 1b, Cai et al. synthesized hollow manganese Prussian white nanocapsules (HMPWCs), which can achieve the purpose of alleviation of cognitive decline and attenuation of Tau-related pathology [7].

Although the current research on $\mathrm{AD}$ is being further advanced, it still needs major breakthroughs. Combining the clinical features of $\mathrm{AD}$, finding specific biological markers and multi-modality imaging examination, establishing accurate early diagnosis technology, and realizing the early diagnosis of the disease to prescribe medicine according to the symptoms can greatly improve the patient's life treatment and reduce the burden on the family.

\subsubsection{Parkinson's Disease (PD)}

Parkinson's disease (PD) is the second most common neurodegeneration after AD [8]. Genes, aging, and environmental factors play an important role in the development of PD. PD is the gradual loss of Pars compacta dopaminergic neurons, leading to a decrease in dopamine levels, which can lead to severe motor dysfunction. It is characterized by hypokinesia and hyperkinesia, such as myotonia, bradykinesia, and resting tremor [9-11]. As the disease progresses, the patient's exercise capacity will gradually be lost. In the late stage, some patients even suffer from muscle atrophy and the inability to move the joints, which brings heavy physical and psychological pressure to the patients [12]. Therefore, finding effective drugs to treat PD is extremely urgent, which requires scientific researchers to continuously research new drugs and develop new therapies.

At present, the traditional treatment of PD is mainly drug therapy and non-drug therapy [13]. However, drug treatments can only slightly control the patient's initial symptoms because drugs cannot prevent or delay the degenerative changes of dopaminergic neurons $[14,15]$. Non-drug treatments include rehabilitation training, diet therapy, gene therapy, and surgery. However, these treatments have not achieved satisfactory results. As a result, multidisciplinary researchers have been committed to the development of new drugs for the treatment of PD.

Sun's group used gold nanoclusters (AuNCs) as anti-PD drugs for the first time. At the same time, AuNCs can cross the BBB, and the elimination half-life of drug metabolism is $9.317 \pm 0.681 \mathrm{~h}$. This research opens up a new way for the development of anti-PD drugs and also expands the application prospects of AuNCs in the field of medicine [16]. In addition to overcoming BBB delivery of drugs, researchers have prepared oral nanoparticles that overcome the gastrointestinal barrier and deliver drugs into the brain to treat PD. As shown in Figure 1c, Chen et al. synthesized a six-arm star polymer, then loaded puerarin by anti-solvent precipitation method, and coated the nanoparticles with D- $\alpha$-tocopherol $\mathrm{PEG}_{1000}$ succinate. Pharmacokinetic studies have found that after oral administration of nanoparticles, the drug concentration in the blood and brain is significantly increased, and the biological half-life is also prolonged. The results showed that the drug-loaded nanoparticles improved PD-related motor dysfunction and reversed the content of dopamine and its metabolites [17].

At present, researchers have conducted extensive studies on the molecular mechanism of PD and have also made progress in gene therapy [18]. Clare L. Parish et al. introduced the suicide gene (HSV-TK) into the transplanted cells and induced the expression of the suicide gene at a specific time point through drug induction. In order to achieve the purpose of reducing the growth of non-target cells and enriching dopaminergic neurons in the substantia nigra compact part [19]. In addition, the development of imaging has further promoted the treatment of PD. Evidence from dopaminergic images and cerebral blood flow / metabolism images reveals the differences in cognitive physiology between healthy people and those with PD [20]. We believe that with the in-depth research on the mechanism of PD and the development of visualized multi-modal treatment methods, PD patients will be cured gradually. 


\subsubsection{Ischemic Stroke (IS)}

Cerebrovascular disease, also known as stroke, has become the second leading cause of death and the third leading cause of disability worldwide [21]. Among them, ischemic stroke (IS) is the disease with the highest disability rate in a single disease, and it is also the main type of stroke in clinical practice. In recent years, the incidence of IS is increasing at an annual rate of $8.7 \%$, which has brought huge mental torture and financial burden to patients and their families. Therefore, it is urgent to develop new treatment methods to enhance the cure of stroke [22].

Nowadays, IS is mainly treated by intravenous thrombolytic therapy and intravenous administration [23]. Although thrombolytic therapy as the gold standard can effectively achieve vascular recanalization and reduce the mortality of patients, due to the existence of reperfusion injury, patients often experience further deterioration of brain damage and limited blood perfusion after vascular unblocking. The phenomenon of "no-reflow" makes nearly half of the patients become disabled, which seriously affects the prognosis and quality of life [24,25]. From the intravenous administration of small molecule neuroprotective drugs due to the blocking effect of $\mathrm{BBB}$, the intake of cerebral infarction sites is relatively small, and large doses are required, which can easily lead to kidney function damage and induce side effects such as skin rashes [26,27]. These are clinical unsolved problems of treating stroke.

At the molecular level, the core of the onset of IS is neuronal damage caused by excessive ROS [28]. Therefore, the research of free radical scavengers has become a research hotspot in the neuroprotective treatment of IS. When a brain disease occurs, it is often difficult for drugs delivered by intravenous injection to pass through the BBB to reach the location of the lesion, resulting in a sharp decline in the efficacy of the drug. The rapid development of nano-drug carriers provides the possibility for the development of new targeted drugs.

In recent years, research on brain-targeting carrier materials has become more and more in-depth. Liposomes, polymer nanoparticles, and artificial membrane materials have all shown certain brain-targeting capabilities. These improved MSCs have achieved significant results in mice with IS, which is superior to the therapeutic effect of natural stem cells [29]. In addition, inorganic nanomaterials can be designed as drug delivery carriers of different sizes, shapes, and surface charges. Through surface functionalization and group modification, they can specifically target brain cells to enhance their efficiency across the $\mathrm{BBB}$, prompting the rapid concentration of drugs in the brain injury area, thereby improving the therapeutic effect [30]. From Figure 1d, a non-viral and magnetic fieldindependent gene transfection strategy is reported. They used ferrous magnetic iron oxide nanochains to improve natural mesenchymal stem cells (MSCs) derived from embryos. The nano-chain can be used as a gene delivery carrier, which realizes high-efficiency gene recombination for MSCs without relying on an external magnetic field, simplifies the current magnetotransfection process based on magnetic nanoparticles, and avoids the use of external magnetic fields that may cause adverse effects on stem cells [29]. This provides new research ideas for improving the efficacy of stem cell therapy. 
(a)

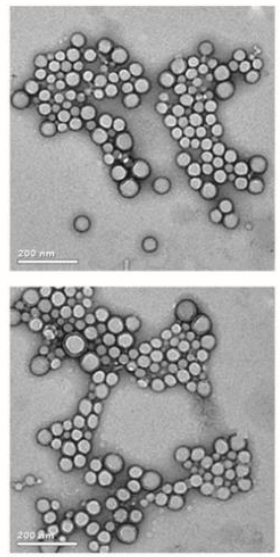

(c)

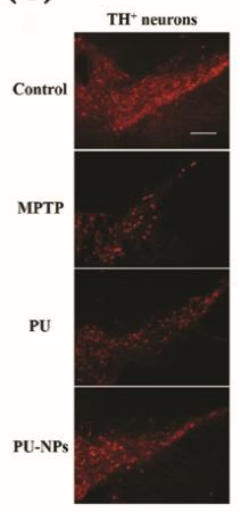

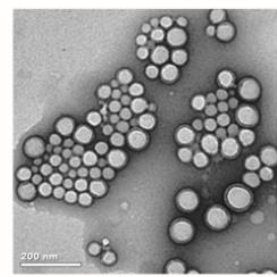

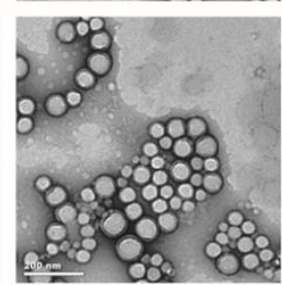

(b)

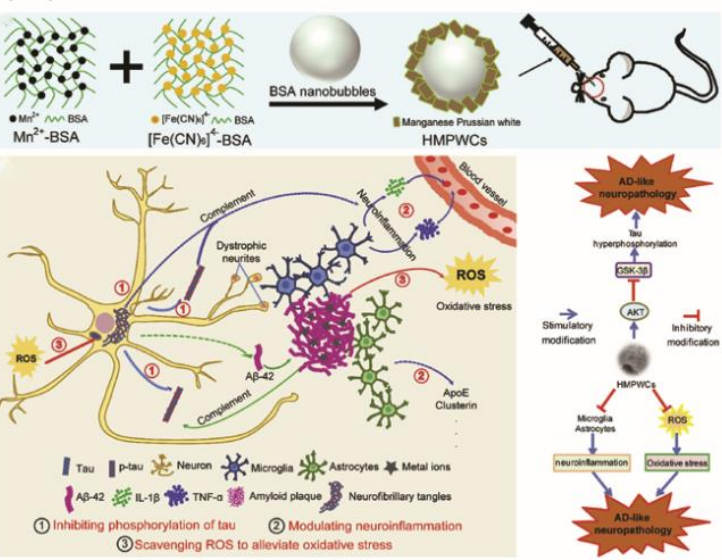

(d)
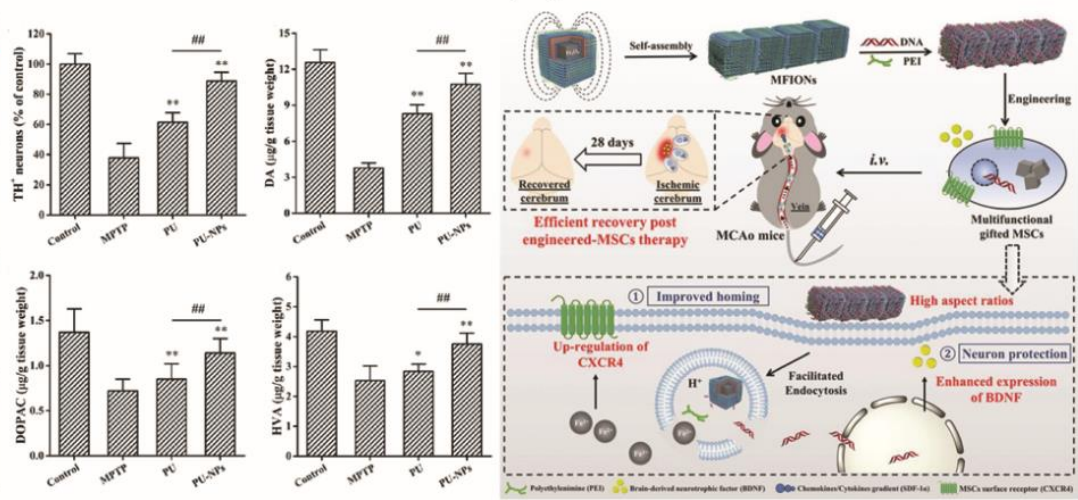

Figure 1. (a) Transmission electron micrographs of $\mathrm{NP}, \mathrm{T}_{3}-\mathrm{NP}, \mathrm{Q}_{3}-\mathrm{NP}$, and $\mathrm{T}_{3} \mathrm{Q}_{3}-\mathrm{NP}$, respectively, reprinted from [5]. Copyright 2014, with permission from Elsevier; (b) schematic illustration of the preparation of HMPWCs and the effect of HMPWCs on the Tau-related AD-like neuropathology, reprinted from [7]. Copyright 2020, with permission from Elsevier; (c) PU-NPs reduce neurotoxicity induced by MPTP, reprinted with permission from [17] Copyright (2019) American Chemical Society; (d) schematic illustration of MFION-based engineering of MSCs for the recovery post-ischemic stroke, reprinted from [29]. Copyright 2019, with permission from Weily. ${ }^{* *} p<0.01$ corresponds to different treatments vs. MPTP group; \#\# $p<0.01$ corresponds to treatment with PU-NPs vs. with PU group.

\subsubsection{Glioma (GBM)}

Glioma (GBM) is the most common and aggressive tumor in the central nervous system, and it is still clinically incurable [31,32]. Under the premise of protecting brain function as much as possible, tumor removal to the greatest extent, postoperative concurrent radiotherapy, and chemotherapy is the standard treatment for GBM, but the recurrence rate of patients is still close to $100 \%$. In addition, this treatment has a very poor prognosis, with a median survival time of only 9-12 months and a 2-year survival rate of only $8-12 \%$ [33-35]. This is largely due to the existence of the BBB, which severely limits the successful delivery of diagnostic and therapeutic molecules (drugs, MR contrast agents, etc.) to the brain, thereby affecting the diagnosis and treatment of GBM [36].

In order to achieve high-efficiency treatment of GBM, Shi et al. designed a small interfering RNA (siRNA) delivery system disguised as red blood cell membrane (RBCm) for gene therapy of GBM. The multifunctional biomimetic siRNA nanocomposite effectively solves the current problems of a short half-life, poor BBB penetration, insufficient tumor accumulation, and poor cellular uptake faced by siRNA, and can realize the efficient treatment of glioma [37]. The combination of Transferrin (Tf) and Tf receptors (TfRs) overexpressed on the surface of BBB endothelial cells is one of the methods to effectively cross the BBB $[38,39]$. Chen et al. adopted a gentle biomimetic mineralization strategy to 
grow $\mathrm{MnO}_{2}$ nanocrystals in situ on iron-saturated transferrin and further efficiently load the sonosensitizer protoporphyrin. The preparation method well maintains the ability of transferrin itself to cross the BBB and target GBM and endows it with high specific T1weighted magnetic resonance imaging (MRI) signal enhancement and high specificity in response to the GBM microenvironment. High-efficiency ultrasound dynamic therapy [40]. What is important is that this Tf -based integrated diagnosis and treatment nano-agent has excellent biological safety and versatility, shows good clinical potential, and provides a useful reference for the efficient diagnosis and treatment of a variety of brain diseases.

\section{Traditional Imaging Techniques}

This section may be divided into subheadings. It should provide a concise and precise description of the experimental results, their interpretation, as well as the experimental conclusions that can be drawn.

\subsection{Magnetic Resonance Imaging (MRI)}

MRI, as a commonly used clinical imaging and diagnostic technique, plays an important role in the early diagnosis of diseases. MRI is a physical phenomenon. As an analysis method, it is widely used in physics, chemical biology, and other fields. It was not used for medical clinical testing until 1973. In order to avoid confusion with radiography in nuclear medicine, it is called MRI. The best results are the brain, its spinal cord, heart, and great blood vessels, joint bones, soft tissues, and pelvis. For cardiovascular diseases, it can not only observe the anatomical changes of various chambers, large blood vessels, and valves but also perform ventricular analysis for qualitative and semi-quantitative diagnosis. It can make multiple cross-sectional views with high spatial resolution [41,42].

At present, small molecule gadolinium (Gd) complexes are the main clinical contrast agents. After intravenous injection, the contrast agent is quickly distributed throughout the body through the blood circulation and can spread to the extracellular space, and then is quickly excreted from the body by the kidneys [43]. However, these extracellular contrast agents have problems, such as a short half-life and low relaxation rate, which, in turn, leads to weaker and faster attenuation of the MRI enhancement signal in the body, and it is difficult to maintain high-resolution magnetic resonance imaging. At the same time, unreasonable dose control or excessive use of contrast agents can cause toxic side effects [44]. Therefore, a lot of research has been devoted to the preparation of new contrast agents with high relaxation rates and meeting the basic requirements of contrast agents.

\subsection{Computed Tomography (CT)}

Computed Tomography (CT) uses precisely collimated X-ray beams, gamma rays, ultrasound, etc., together with a highly sensitive detector to scan a certain part of the human body one by one. It has the characteristics of fast scanning time and clear images. It can be used for the inspection of various diseases [45]. In order to obtain more accurate and clear CT imaging effects, CT contrast agents are particularly important. According to the rules of X-ray absorption coefficient, materials with higher density or high atomic number can be used as CT contrast agents [46]. Currently, CT imaging contrast agents used in clinical practice are mainly triiodobenzene derivatives, such as iohexol and iomeprol. However, these small molecule CT contrast agents have problems such as poor targeting and rapid renal clearance during clinical use [47]. Therefore, we must work hard to develop CT imaging contrast agents that are safe and highly targeted as soon as possible.

\subsection{Fluorescence Imaging (FL)}

Fluorescence imaging (FL) is an optical imaging technology that uses fluorescent probes to label cells or specific molecules to generate fluorescent signals under the excitation of external light to achieve imaging [48]. Because of the low cost, convenient operation, quantitative sensitivity, and inherent biological safety of fluorescence imaging, it has been widely used in the field of biological imaging [49-51]. Common fluorescent probes 
mainly include organic fluorescent dyes, fluorescent proteins, and fluorescent lanthanide compounds [52-54]. FL has the advantages of high sensitivity and fast imaging. However, in vivo FL faces the problems of biological endogenous fluorescence signal interference, photobleaching, and fluorescence quenching. Therefore, near-infrared fluorescent probes with the advantages of deep imaging penetration depth and good signal-to-noise ratio have become research hotspots [52,55].

\subsection{Positron Emission Computed Tomography (PET)}

Positron emission computed tomography (PET) is an important part of nuclear medicine molecular imaging technology [56]. PET is the only new imaging technology that can display the metabolism of biomolecules, receptors, and nerve mediators in the living body. It has been widely used in the diagnosis and differential diagnosis of various diseases, disease judgment, curative effect evaluation, organ function research and new drug development, etc. It has the advantages of high sensitivity, good specificity, whole-body imaging, and high safety. In recent years, PET has played a more important role in tumors, neurological diseases, and cardiovascular diseases $[57,58]$.

Now, more and more PET tracers can reflect amino acid metabolism, accounting metabolism, and antisense imaging in vivo. However, no PET tracer can target tumors to enter clinical application at home and abroad. Therefore, it is of far-reaching significance to develop a tumor-targeted PET tracer with my country's independent intellectual property rights to improve the early detection, early diagnosis, and early treatment of tumors in our country.

\subsection{Photoacoustic Imaging (PA)}

Photoacoustic imaging (PA) is a new non-invasive and non-ionizing biomedical imaging method, which surpasses the depth limitation of traditional ballistic optical imaging and the resolution limitation of diffuse optical imaging [59]. The photoacoustic signal generated by the biological tissue carries the light absorption characteristic information of the tissue. By detecting the photoacoustic signal, the light absorption distribution image in the tissue can be reconstructed, which can reflect the morphological structure, pathological characteristics, and metabolism of the biological tissue to a certain extent. PA imaging combines the advantages of high selectivity in pure optical tissue imaging and deep penetration in pure ultrasound tissue imaging to obtain high-resolution and high-contrast tissue images [60,61]. Therefore, it has been more and more widely used in clinical research, especially scientific research [62].

\subsection{Ultrasound Imaging (US)}

Ultrasound imaging (US) is the use of ultrasonic sound beams to scan the human body through the reception and processing of reflected signals to obtain images of internal organs [63]. Ultrasound Doppler is a detection technology that has developed rapidly in recent years. With the advancement of electronics, this method has been widely used in clinical practice. It is of great value in the examination of flow supply, blood supply of space-occupying lesions, and fetal blood circulation [64,65].

As we all know, single-mode imaging methods have their own characteristics, but they also have characteristics, such as low sensitivity and low spatial resolution [66]. Therefore, the gradually developed multi-modal imaging method can more accurately diagnose the location of the lesion and related information. With the development of imaging medicine and multi-modal visualization technology, rapid and accurate diagnosis of major diseases will become possible, laying a good foundation for precise treatment.

\subsection{Others Imaging Techniques}

Magnetic resonance spectroscopy (MRS) is a functional imaging technology that can provide spatially encoded metabolic information and biochemical changes so as to achieve the purpose of non-invasive diagnosis of diseases. At present, MRS is widely used in the 
diagnosis of central nervous system diseases, especially glioma diseases $[67,68]$. Besides, magnetic particle imaging (MPI) is a new type of biomedical imaging technology. Different from traditional MRI, MPI realizes direct imaging of the spatial distribution of magnetic particles by directly detecting changes in the responsiveness of magnetic particles in a magnetic field [69].

\section{The Imaging Applications of Inorganic Nanomaterials in Different Brain Disease Models}

In recent years, different nano-formulations have been or are being developed for use in the diagnosis and treatment of brain diseases. Nanomaterials have different shapes, such as spherical, rectangular, and linear morphologies [70]. Nanomaterials can be easily surfacefunctionalized, which can not only improve the biocompatibility of nanomaterials but also change the charge distribution on the surface of various nanomaterials and achieve a certain degree of targeting or other functional effects [71]. Taking nanomaterials effectively spanning the BBB as an example, the nanomaterials are stable in the blood, have long blood circulation, and cannot cause platelet aggregation. The most important thing is that the modified nanomaterials can achieve the purpose of crossing the BBB at different times through receptor-mediated endocytosis or grafting of some targeting peptides [70,72-74].

The increasing number of non-invasive imaging modes illustrates the need for better imaging modes in medical systems. The research of molecular targeted contrast agents has become the key to multimodal imaging. The characteristics of various inorganic nanomaterials-based imaging modalities in terms of spatial resolution and molecular sensitivity are summarized in Table 1 . Therefore, the following will use inorganic nanomaterials as the starting point to separately illustrate the imaging applications of non-metal-based nanomaterials and metal-based nanomaterials in different brain disease models.

Table 1. The characteristics of various inorganic nanomaterials-based imaging modalities [75].

\begin{tabular}{|c|c|c|c|c|c|}
\hline & Nanomaterial Type & Imaging Modality & Spatial Resolution & $\begin{array}{c}\text { Advantages } \\
\text { (Sensitivity, Imaging } \\
\text { Stability, etc.) }\end{array}$ & References \\
\hline \multirow{2}{*}{ Nonmetallic- based } & $\begin{array}{l}\text { Multi-walled carbon } \\
\text { nanotubes } \\
\text { (f-MWNTs) }\end{array}$ & SPECT/CT & $\begin{array}{c}\text { 6-8 mm/ } \\
0.5-0.625 \mathrm{~mm}\end{array}$ & $\begin{array}{l}\text { Fast scanning time and } \\
\text { clear images }\end{array}$ & [76] \\
\hline & $\begin{array}{l}\text { Hollow mesoporous } \\
\text { silica spheres } \\
\text { (HMSN) }\end{array}$ & MRS & - & High sensitivity & [77] \\
\hline \multirow{3}{*}{ Metal-based } & $\mathrm{Fe}_{3} \mathrm{O}_{4}$ & MRI & $1-2 \mathrm{~mm}$ & $\begin{array}{l}\text { High imaging stability } \\
\text { and long-term tracking }\end{array}$ & {$[78,79]$} \\
\hline & BSA-MnO ${ }_{2}$ & MRI & $1-2 \mathrm{~mm}$ & $\begin{array}{c}\text { Strong imaging ability } \\
\text { and good } \\
\text { biocompatibility }\end{array}$ & [80] \\
\hline & Si-AuNRs & PA & $50-200 \mu \mathrm{m}$ & $\begin{array}{l}\text { Non-invasive and } \\
\text { non-ionizing } \\
\text { biomedical imaging }\end{array}$ & [81] \\
\hline
\end{tabular}

\subsection{Nonmetallic-Based Nanomaterials}

\subsubsection{Carbon-Based Nanomaterials}

In recent years, carbon-based nanomaterials have aroused great interest in the fields of neuronal tissue imaging, drug delivery, and electrical sensing [82]. Carbon-based nanomaterials can interact with biological systems at the molecular level and have a high degree of spatial and temporal specificity. They can penetrate the BBB and deliver specific therapeutic drugs, probes, or biological materials to target cells and tissues in the living brain [83].

The elimination and detection of A $\beta$ aggregates are essential for the treatment and diagnosis of AD. According to reports, Sun et al. synthesized Nitrogen-doped carbonized polymer dots (CPDs) by hydrothermal method. CPDs can not only effectively inhibit 
$A \beta$ aggregation and rapidly depolymerize mature $A \beta$ fibers but also realize real-time fluorescence detection of $A \beta$ plaques. As shown in Figure 2a, the green fluorescence signal of ThT-labeled A $\beta 40$ aggregates decreased with the increase in the concentration of CPDs, which was due to the inhibitory effect of CPDs. Additionally, the interaction between CPDs and $A \beta 40$ aggregates resulted in different red fluorescent plaques [84]. In addition to the application of carbon-based nanomaterials in the diagnosis and treatment of $\mathrm{AD}$, they also have great potential in revealing the detailed functions and pathophysiology of the living brain. The combination of nanotechnology and the latest microscopy technology can reveal the complexity of nerve cells and the CNS, which is also conducive to the diagnosis and treatment of brain diseases [85]. For example, amine-functionalized multi-walled carbon nanotubes can exhibit inherent luminescence, and the photon emission falls at 450-650 nm, which is the visible region of the electromagnetic spectrum [86]. Using multiphoton fluorescence technology, intravenously injected multi-walled carbon nanotubes (MWCNTs) can accumulate within $5 \mathrm{~min}$ of injection to achieve brain tissue imaging. Although these results show the promise of in vivo brain imaging, the high absorption and scattering of visible fluorescence limits potential deep imaging applications [76]. Therefore, multi-modal imaging should be developed to achieve precise diagnosis and treatment.

(a)
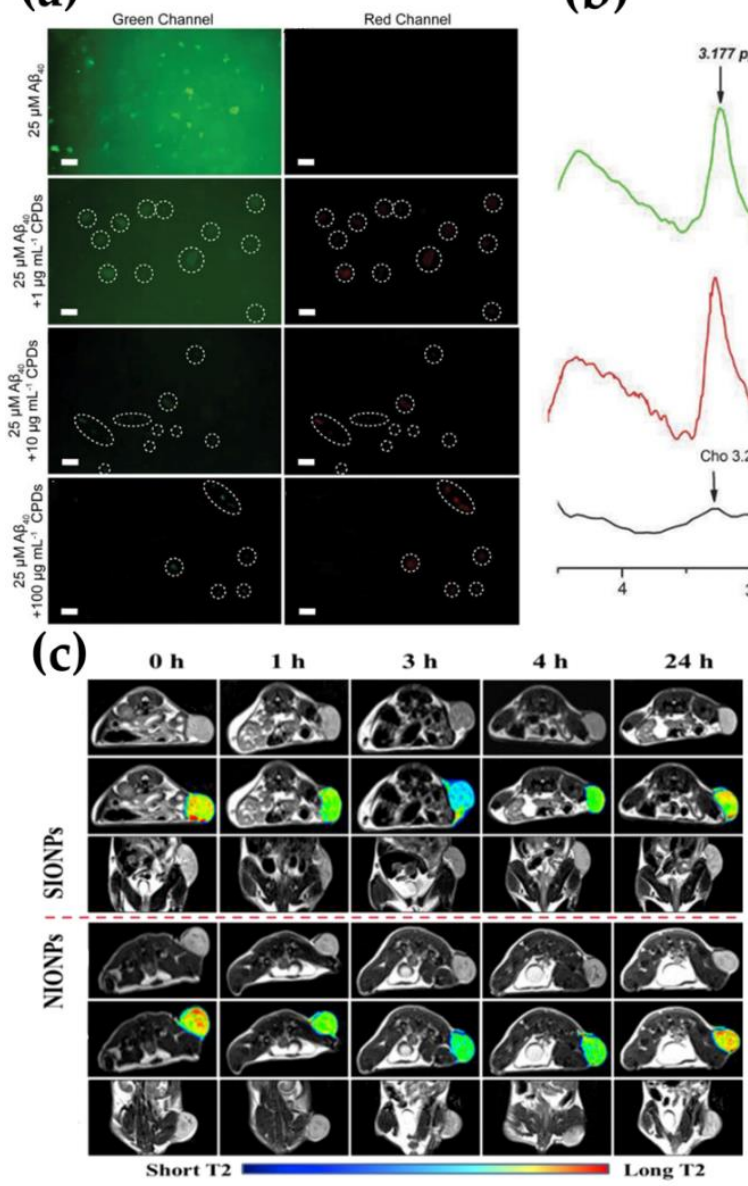

(b)
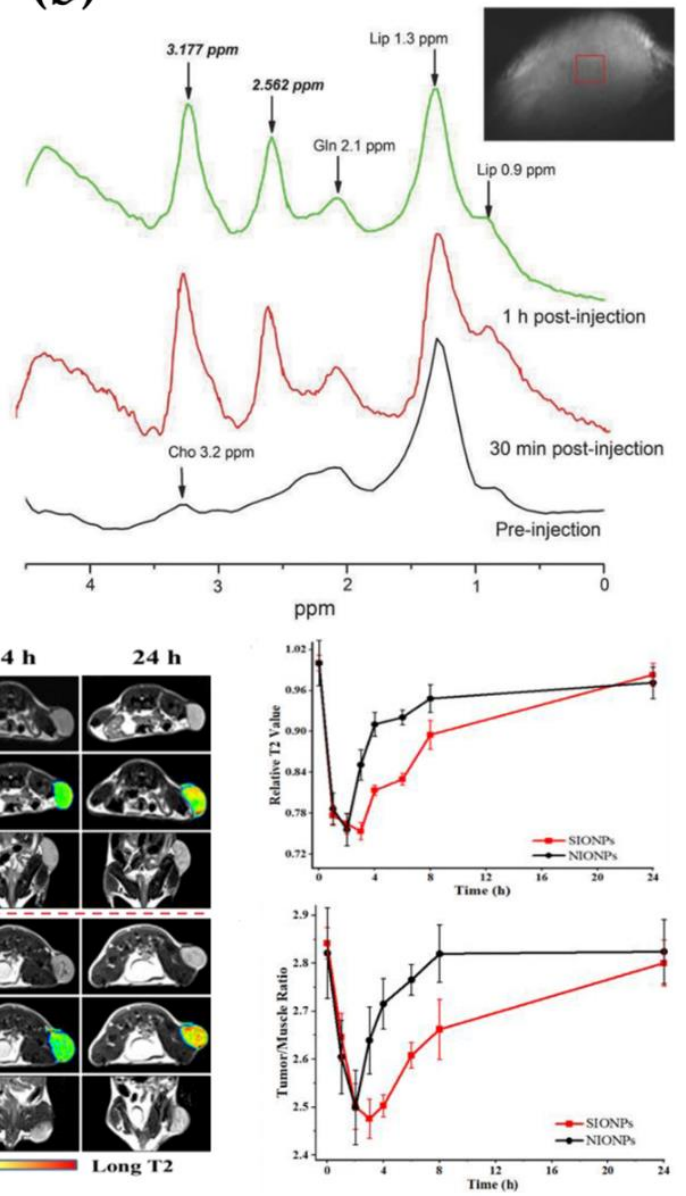

Figure 2. (a) FL of $\mathrm{A} \beta 40$ incubated with or without $\mathrm{CPDs}$ after $56 \mathrm{~h}$ at $37^{\circ} \mathrm{C}$, reprinted from [84]. Copyright 2020, with permission from Weily; (b) MRS spectra of subcutaneously transplanted glioma before and after the intratumoral injection of $1 \mathrm{~mL}$ AMSNs physiological saline solution (10 mg AMSNs/mL, $40 \mathrm{mg}$ AMSNs/kg), reprinted from [77]. Copyright 2018, with permission from Weily; (c) in vivo T2-weighted imaging and the corresponding time course of relative T2 signal intensity of tumors, reprinted from [79]. Copyright 2021, with permission from Elsevier. 


\subsubsection{Silicon-Based Nanomaterials}

Silicon is one of the essential trace elements of the human body, accounting for $0.026 \%$ of body weight. Silicon is related to the formation of connective tissue and cartilage. Due to the stable structure and good biocompatibility of silicon-based materials, silicon-based nanomaterials as carriers are more and more widely used in the medical field.

Traditional magnetic MRS imaging technology is only limited to the detection of endogenous metabolites and cannot accurately distinguish between GBM and other tumors, such as lymphomas and metastases, which greatly limits its application in disease diagnosis [87-89]. Bu's research group proposed the concept of a contrast agent for functional MRS. By loading exogenous $\beta$-alanine on Angiopep-2 (ANG)-modified hollow mesoporous silica spheres (HMSN), the GBM obtained an active targeted and accurate diagnostic function of functional MRS, which found that the GBM lesion area of tumor-bearing mice can show specific $\beta$-alanine peaks, while the normal brain tissue areas did not show. Therefore, this new type of contrast agent with a specific enhanced MRS imaging function will be expected to achieve an accurate imaging diagnosis of GBM. As shown in Figure $2 b, \beta-$ alanine has two characteristic peaks at $2.562 \mathrm{ppm}$ and $3.177 \mathrm{ppm}$. It is the $2.562 \mathrm{ppm}$ peak that distinguishes it from other substances in the brain and has a special enhanced MRS imaging function, which promotes the rapid development of MRS imaging technology in clinical tumor precise imaging diagnosis [77].

\subsubsection{Other Nonmetallic-Based Nanomaterials}

In addition to carbon-based silicon-based and other mainstream non-metal-based nanomaterials used in brain disease imaging, some quantum dots and upconversion luminescent nanomaterials also play an important role. This type of nanomaterial has a wider absorption band and a narrower emission spectrum in the visible-near-infrared spectrum. Therefore, it has greater advantages than organic dyes in the imaging of brain gliomas [90-92].

\subsection{Metal-Based Nanomaterials}

\subsubsection{Iron-Based Nanomaterials}

Iron-based nanomaterials have special physical and chemical properties. In particular, $\mathrm{Fe}_{3} \mathrm{O}_{4}$ nanomaterials have multiple crystal forms. Additionally, the morphology of the nanomaterials is also diversified, thus having different properties. So far, iron-based nanomaterials are widely used in electromagnetics, catalysis, biomedicine, environmental protection, and other related fields. MRI is one of the most important clinical diagnostic methods. The currently commonly used contrast agent is Gd-DTPA, but it has problems, such as poor distribution and high prices [93]. In contrast, iron-based nanomaterials have a high specific distribution in living tissues, so they have broad application prospects. In particular, $\mathrm{Fe}_{3} \mathrm{O}_{4}$ and maghemite $\left(\gamma-\mathrm{Fe}_{2} \mathrm{O}_{3}\right)$-based crystalline particles can be transformed into nanomaterials (3-100 $\mathrm{nm}$ ) with different characteristics by controlling the raw materials, reaction time, and preparation methods. Because both iron oxides contain atomic holes and surface defects, they are easy to be modified for surface functionalization [94-96]. Interestingly, when prepared by conventional methods, $\mathrm{Fe}_{3} \mathrm{O}_{4}$ is magnetic, has a cubic inverse spinel structure, and often has tetrahedral and octahedral positions. After reasonable modification, it can be better dispersed to form a magnetic fluid, which can be imaged under the condition of a magnetic field [97].

The distinction between inflammatory mass and malignant GBM has always been a difficult point in clinical diagnosis. Studies have shown that the lateral relaxation time of $\mathrm{Fe}_{3} \mathrm{O}_{4}$ nanoparticles is closely related to their particle size. $\mathrm{Fe}_{3} \mathrm{O}_{4}$ with a large particle size can significantly shorten the T2 lateral relaxation time, thereby increasing the contrast of MRI [78]. The reduction-responsive amphiphilic polymer mPEG-S-S- $\mathrm{C}_{16}$ was synthesized by Wu's group. The encapsulated $\mathrm{Fe}_{3} \mathrm{O}_{4}$ magnetic nanoparticles can enhance its $\mathrm{T} 2$ lateral relaxation and identify inflammatory masses and malignant gliomas. It can be seen that the T2 signal is significantly enhanced by the reduction-activated concentrated magnetic resonance 
contrast agent used in the imaging of GBM in situ (Figure 2c), the T2 time is shortened by about $75.3 \%$, and the $\mathrm{T} 2$ signal of the inflammatory mass has no obvious change [79].

GBM is the most common brain tumor with a very high fatality rate. It often infiltrates adjacent tissues, and its shape is variable without a definite scope [98,99]. Effective GBM treatment requires sensitive tumor display during surgery and effective postoperative chemotherapy. Unfortunately, the spread and invasiveness of GBM limit the detection of GBM tumors, and current intraoperative visualization methods limit the complete tumor resection. In addition, although chemotherapy is usually used to remove residual cancer tissue after surgery, most chemotherapeutic drugs cannot effectively penetrate the BBB or enter GBM tumors. Therefore, GBM has limited treatment options and a high recurrence rate. It is necessary to improve its complete visualization during surgery and treatment [100-102]. In addition to MRI, near-infrared fluorescence (NIRF) imaging is also an important diagnostic method for GBM tumors. In addition to MRI, NIRF is also an important diagnostic method for GBM. Compared with MRI, NIRF can clearly distinguish the boundaries of the tumor so that the surgeon can effectively remove the tumor [103]. Combine ferumoxytol (FMX) with NIRF ligand hepthamethine (HMC) to construct HMCFMX nano-platform. The experimental results show that HMC-FMX nanoparticles pass through the BBB and selectively aggregate in the tumor, which makes it possible to visualize the tumor tissue infiltration based on NIRF (Figure 3a) [104].

It is well known that iron oxide nanoparticle (IONP) is often used as an MRI contrast agent. In recent years, magnetic particle imaging (MPI) has attracted much attention because of its high sensitivity, and IONP can be used as a tracer of MPI. The tracer generates non-linear magnetization signals in an oscillating magnetic field for performing imaging, especially for stem cell tracking applications $[105,106]$. It is expected that in the near future, the development of iron-based nanomaterials can have a major breakthrough. It will also have a better application in the diagnosis and treatment of brain diseases such as AD, PD, and IS.

\subsubsection{Manganese-Based Nanomaterials}

Manganese is an essential trace element for the human body. It is indispensable for the maintenance of normal brain function. It has a certain relationship with the development of intelligence, thinking, emotion, and behavior. Manganese is also very important for the work of the human brain and CNS and has a certain effect on AD. Interestingly, there is a superoxide dismutase in the human body, which is the most important protective enzyme in the life of the human body, and this enzyme must be catalyzed by manganese ions to function. With the development of nanotechnology, manganese-based nanomaterials are playing an increasingly important role in building an integrated platform for diagnosis and treatment.

The current Gd chelate-based MRI for stroke has relatively low sensitivity and can cause side effects, such as nephrogenic systemic fibrosis and intracranial gadolinium deposition [70,107-110]. Therefore, it is urgent to promote new and safer research imaging methods for the diagnosis and analysis of stroke. In recent years, manganese-based nanomaterials have become an integrated diagnosis and treatment nano-platform in the field of biomedicine due to their unique biological effects, such as paramagnetism, catalysis, and redox [111]. As shown in Figure $3 b, c$, the $B S A-\mathrm{MnO}_{2}$ nanoparticles prepared by Pan's group use the one-pot method and can image the permeability of the BBB in stroke. The nanoparticle has strong imaging ability and good biocompatibility, can image the permeability of the BBB of the middle cerebral artery occlusion (MCAO) model rat in a non-invasive and timely manner, and plays a good predictive role [80]. Chen et al. used a similar protein modification strategy. They have successfully grown $\mathrm{MnO}_{2}$ nanocrystals on holo-transferrin (holo-Tf) in situ under milder conditions $(\mathrm{pH}=8.4)$, which preserved the structure of $\mathrm{Tf}$, thereby keeping it across the BBB and targeting the brain glue. Secondly, protoporphyrin (PpIX) was further loaded on holo-Tf as a sonosensitizer to obtain $\mathrm{MnO}_{2} @ \mathrm{Tf}$-ppIX composite nanoparticles (TMPs). $\mathrm{Mn}^{2+}$ can be released from TMPs in the tumor microenvironment so as to realize the enhancement of MRI signal in response to the microenvironment [40]. 
It is precisely because of the rich biological properties of $\mathrm{Mn}^{2+}$ and its potential as a contrast agent for MRI that manganese ion-enhanced magnetic resonance imaging (MEMRI) has applications in neuroimaging. Because toxicity is a major drawback of manganese ion contrast agents, enormous toxicity will limit its application. Manganesebased nanomaterials must be safely transported to the lesion site based on ensuring its imaging capabilities to exert their diagnostic effect [112]. An accurate diagnosis of neuroimaging will also guide the diagnosis and treatment of brain diseases.

(a)

(b)

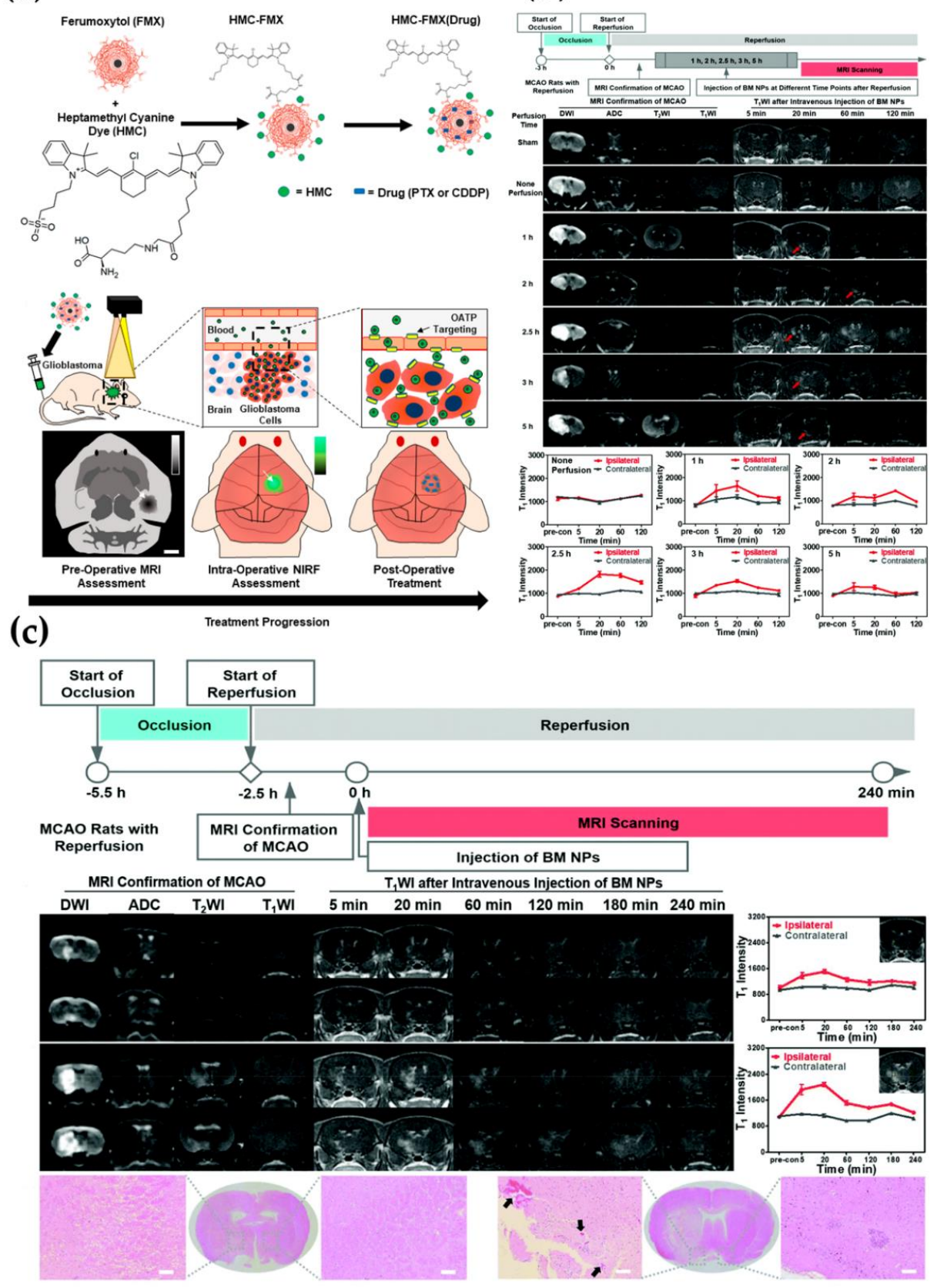

Figure 3. (a) HMC-FMX facilitates GBM tumor detection and drug delivery across the BBB, permission from [104]. Copyright (2020) American Chemical Society; (b) MR imaging of BBB permeability in MCAO rats without perfusion or with different perfusion time points $(1,2,2.5,3$, and $5 \mathrm{~h}$ ) postinjection of BM NPs, permission from [80]. Copyright (2021) Royal Society of Chemistry; (c) BBB permeability imaging indicated by the BM NPs in MCAO rats with or without HT, permission from [80]. Copyright (2021) Royal Society of Chemistry. 


\subsubsection{Gold-Based Nanomaterials}

In recent years, there are many types of research on gold $(\mathrm{Au})$ nanomaterials. Because gold nanomaterials are chemically inert relative to other metal materials, the surface can be easily modified, and it can be synthesized into nanoclusters [113], nanorods [114], and nanostars [115]. Meanwhile, Au nanomaterials have surface plasmon resonance (SPR) characteristics, which is one of the optical properties of Au nanomaterials [116]. Therefore, it has a wide range of applications in cell imaging, ultra-sensitive detection, drug delivery, and photothermal therapy [117-120]. It is this unique optical property that makes Au nanoparticles worthy of in-depth research in imaging, such as PA [121-123]. In addition, Au nanoparticles can also be used as a diagnosis pattern of CT [124]. Due to the existence of $\mathrm{BBB}$, the application of nanomedicine in brain diseases has been limited. Thus, Madhavan Nair et al. synthesized magnetic core/Au shell (MNP@Au) plasmonic nanoparticles with super-transient magnetism, which is helpful for MRI. In addition, the experiment also studied the migration experiment of MNP@Au nanoparticles in BBB in vitro. The experimental results show that the presence of the magnetic field increases the migration of MNP@Au nanoparticles and does not affect the integrity and permeability of the BBB [125]. In addition to magnetic targeting, using focused ultrasound to open the BBB instantaneously is also one of the better drug delivery methods $[126,127]$. Stanislav Y Emelianov and others synthesized silica-coated Au nanorods (Si-AuNRs) and explored the ability of the nanomaterial to be delivered to local areas of the brain under the stimulation of focused ultrasound. Furthermore, this nanomaterial has the ability of US and PA [81], which may be a powerful tool for understanding the mechanisms of neurological diseases and evaluating the effects of treatment.

Au-based nanoparticle with MRI-PA-Raman imaging function can better delineate the edge of brain tumors and has high sensitivity [128]. This method might guide the resection of brain tumors well in the future. However, Au-based nanoparticles still face some challenges, which we must solve in recent years. For example, if the concentration of Au nanoparticles is low, the effect of PA imaging will not good enough. So far, although the clinical transformation of Au-based nanoparticles has been limited, we can further upgrade the modification of the Au surface and then synthesize a suitable shape and optimize its optical effect. If we do that successfully, AuNP-based PA imaging will come true.

\subsubsection{Other Metal-Based Nanomaterials}

Traditional NIRF imaging mainly focuses on near-infrared imaging (NIR-I, 700-900 nm). Due to the strong absorption and high scattering of NIR-I light by biological tissues and the limited penetration depth of NIR-I light, these deficiencies have led to the need to further improve the resolution and sensitivity of NIR-I fluorescence imaging, which hinders the development of FL imaging technology in the deep tumors, such as GBM applications. Therefore, NIRF imaging has gradually expanded from NIR-I to the near-infrared second zone (NIR-II, 1000-1700 nm) with deeper penetration depth, less photon tissue attenuation, and higher temporal and spatial resolution [129-131]. In NIR-II imaging, rare-earth iondoped nanoparticles are used as a new type of fluorescent nanoprobe, which has a larger Stokes shift, less biological toxicity, better photostability, and narrower emission advantages, such as spectrum. However, due to the relatively low quantum fluorescence yield of rare-earth nanoparticles, especially the long-wavelength NIR-II emission, their application in NIR-II bioimaging is limited [132,133]. According to a report, $\mathrm{NaNdF}_{4} @ \mathrm{NaLuF}_{4}$ nanoparticles were synthesized to enhance the fluorescence intensity [134]. This will facilitate imaging in areas of glioma. CT/MRI dual-modality imaging of the lesion area will be more conducive to the diagnosis of GBM. Wang's research group created a polydopamineAu nanoparticle composite platform loaded with Pifthrin- $\mu$, which combines photothermal therapy and radiotherapy and, at the same time, enhances the proapoptotic unfolded protein response of GBM after treatment and significantly improves the therapeutic effect. The Au nanoparticles at the core of the nanoplatforms can be used for CT imaging, and the polydopamine layer on the surface can be used for MR T1-weighted imaging. The 
results of the study show that after the tail vein injection of the nanomaterial, CT/MRI dual-modality imaging of brain GBM can be carried out, thereby guiding radiotherapy and photothermal therapy and realizing the integration of diagnosis and treatment [135].

According to reports, cerium oxide $\left(\mathrm{CeO}_{2}\right)$ can be used as good medicine for the treatment of brain diseases. Shi et al. used ultra-small $\mathrm{CeO}_{2}$ nanoparticles $(3-5 \mathrm{~nm})$ as the core and grafted PEG and ANG polypeptides on the surface to achieve receptor-mediated endocytosis across the BBB. The active site $\mathrm{Ce}^{3+} / \mathrm{Ce}^{4+}$ electron pair on the surface of the nanomaterial has a strong antioxidant capacity and can effectively scavenge free radicals. Meanwhile, the loaded edaravone (Eda) further scavenges the ROS in the IS region [136]. Doping single atoms on the surface of $\mathrm{CeO}_{2}$ nanoparticles is one of the effective strategies to improve their catalytic activity. According to reports, Zhang et al. synthesized a Pt/ $\mathrm{CeO}_{2}$ nanoenzyme. Single-atom $\mathrm{Pt}$ caused $\mathrm{CeO}_{2}$ lattice expansion and preferential distribution, which greatly improved its endogenous catalytic activity and achieved the purpose of treating brain trauma [137]. In future research, we can also develop the possibility of multi-modal imaging based on $\mathrm{CeO}_{2}$ nanoparticles.

\section{Summary and Outlook}

In the past few decades, the development of nanomaterials and nanotechnology has gradually increased, and there has been greater progress in biomedical engineering, especially in brain diseases such as IS and AD. In the future, scientists will further accurately design the properties of nanomaterials according to the characteristics of clinical diseases so as to achieve the purpose of precise treatment. In order to clarify the structure and function of the human brain, as well as the material basis of human behavior and mental activity, clarify its mechanism at various levels, improve the efficiency of human neural activity, and improve the level of prevention, diagnosis, and treatment of neurological diseases $[120,121]$. In the 21st century, countries have entered the era of brain science. This will further promote research on the difficulty of nanomaterials effectively crossing the BBB so that nanomaterials achieve effective targeting across the BBB to the lesion as expected. However, we currently lack a deeper safety assessment of the pharmacokinetics, biodistribution, genetic toxicity, and reproductive toxicity of nanomaterials at the biological level. Although we are currently evaluating the safety and therapeutic effects of a series of nanomaterials at the animal level, the current sample data and research progress are difficult to advance into the clinic.

The integrated research of diagnosis and treatment of brain diseases is a new technology that integrates the diagnosis and treatment of diseases [122]. By rationally designing and synthesizing nanomaterials, integrating the current clinically independent diagnosis and treatment processes or functions into the same nanocarrier can build an integrated diagnosis and treatment platform. This not only enables a real-time and accurate diagnosis of diseases while performing disease treatments but also enables monitoring the treatment process and treatment effects, which is conducive to the development of better treatment plans [61,123]. Nanocarriers have become an ideal element of an integrated diagnosis and treatment nano-platform due to their good biocompatibility, modifiability, and excellent loading capacity. At the same time, different nanomaterials have different imaging functions, and some material systems even have multiple imaging functions.

At present, although the construction of integrated diagnosis and treatment nanomaterials faces many challenges, this intelligent diagnosis and treatment nanomaterial has great development potential. With the increasingly urgent clinical needs and the rapid development of science and technology, the development of a new diagnosis and treatment platform based on personalized precision medicine is the general trend. It is a good choice to continuously develop new imaging and treatment modes based on the optical, acoustic, and magnetic properties of nanomaterials. 


\section{Conclusions}

In summary, we discussed some imaging applications of inorganic nanomaterials in different brain disease models. The use of inorganic nanomaterials with unique physicochemical characteristics can improve the imaging resolution and signal-to-noise ratio for the diagnosis of brain disease. Moreover, these non-metallic-based nanomaterials or metal-based nanomaterials can cross BBB in brain diseases by the magnetic field, focused ultrasound, receptor-mediated endocytosis, etc. We also highlighted diverse theranostic nanomaterials with multifunctional properties, which have both multi-mode imaging functions and good treatment effects. More efforts are required to develop better biocompatibility and real-time monitoring of the state of the microenvironment in the lesion area. Although the current imaging research of inorganic nanomaterials for brain diseases is still in the preliminary stage, it is also facing many challenges, such as biological safety and clinical translation. We should explore the application potential of nanomaterials on the basis of many studies and further test its underlying mechanisms. In addition to studying its targeting to different lesion sites, we should also study its ability to cross barriers. Although considering the interdisciplinary development of nanotechnology, biotechnology, and imaging omics, we believe that inorganic nanomaterials will truly move from the laboratory to clinical research to be open to the public and bring good news to patients with brain diseases.

Author Contributions: Investigation, W.D. and L.Z.; formal analysis, W.D.; data curation, Q.Z. and X.L.; writing — original draft preparation, L.Z. and W.D.; writing—review and editing, X.W.; supervision, Y.L.; project administration, Y.L.; funding acquisition, Y.L. All authors have read and agreed to the published version of the manuscript.

Funding: This research was funded by the National Natural Science Foundation of China, No.81871329, the National Natural Science Foundation of China, No. 81671673, and New Developing and Frontier Technologies of the Shanghai Shen Kang Hospital Development Center, No. SHDC12018117.

Institutional Review Board Statement: Not applicable.

Informed Consent Statement: Not applicable.

Data Availability Statement: Not applicable.

Acknowledgments: The authors express their sincere thanks to those involed in helpful discussions.

Conflicts of Interest: The authors declare no conflict of interest.

Sample Availability: Samples of the compounds are available from the authors.

\section{References}

1. Sharma, M.; Dube, T.; Chibh, S.; Kour, A.; Mishra, J.; Panda, J.J. Nanotheranostics, a future remedy of neurological disorders. Expert Opin. Drug Deliv. 2019, 16, 113-128. [CrossRef] [PubMed]

2. Krajcovicova, L.; Mikl, M.; Marecek, R.; Rektorova, I. Disturbed default mode network connectivity patterns in alzheimer's disease associated with visual processing. J. Alzheimers Dis. 2014, 41, 1229-1238. [CrossRef] [PubMed]

3. Dubois, B.; Feldman, H.H.; Jacova, C.; Hampel, H.; Molinuevo, J.L.; Blennow, K.; Bateman, R.; Cappa, S.; Galasko, D.; Cummings, J.L.; et al. Advancing research diagnostic criteria for Alzheimer's disease: The IWG-2 criteria. Lancet Neurol. 2014, 13, 614-629. [PubMed]

4. Fehervari, Z. Blood-brain barrier integrity. Nat. Immunol. 2018, 20, 1. [CrossRef]

5. Zhang, C.; Wan, X.; Zheng, X.; Shao, X.; Liu, Q.; Zhang, Q.; Qian, Y. Dual-functional nanoparticles targeting amyloid plaques in the brains of Alzheimer's disease mice. Biomaterials 2014, 35, 456-465. [CrossRef] [PubMed]

6. Du, Z.; Gao, N.; Guan, Y.; Ding, C.; Sun, Y.; Ren, J.; Qu, X. Rational design of a "sense and treat" system to target amyloid aggregates related to Alzheimer's disease. Nano Res. 2018, 11, 1987-1997. [CrossRef]

7. Cai, X.; Zhang, K.; Xie, X.; Zhu, X.; Feng, J.; Jin, Z.; Zhang, H.; Tian, M.; Chen, H. Self-assembly hollow manganese Prussian white nanocapsules attenuate Tau-related neuropathology and cognitive decline. Biomaterials 2020, 231, 119678. [CrossRef]

8. Ozansoy, M.; Başak, A.N. The Central Theme of Parkinson's Disease: $\alpha$-Synuclein. Mol. Neurobiol. 2012, 47, 460-465. [CrossRef] [PubMed]

9. Huang, C.-S.; Wang, G.-H.; Yeh, J.-Y.; Lai, Y.-C.; Yang, Y.-C. Conveyance of cortical pacing for parkinsonian tremor-like hyperkinetic behavior by subthalamic dysrhythmia. Cell Rep. 2021, 35, 109007. [CrossRef] 
10. Kubrusly, R.C.C.; Guimaraes, M.Z.; Vieira, A.P.B.; Hokoç, J.N.; Casarini, D.E.; De Mello, M.C.F.; De Mello, F.G. 1-DOPA supply to the neuro retina activates dopaminergic communication at the early stages of embryonic development. J. Neurochem. 2004, 86, 45-54. [CrossRef]

11. Reis, R.A.; Ventura, A.L.M.; Kubrusly, R.C.; de Mello, M.C.F.; de Mello, F.G. Dopaminergic signaling in the developing retina. Brain Res. Rev. 2007, 54, 181-188. [CrossRef] [PubMed]

12. Dzamko, N.; Geczy, C.; Halliday, G. Inflammation is genetically implicated in Parkinson's disease. Neuroscience 2015, 302, 89-102. [CrossRef]

13. Aarsland, D.; Creese, B.; Politis, M.; Chaudhuri, K.R.; Ffytche, D.H.; Weintraub, D.; Ballard, C. Cognitive decline in Parkinson disease. Nat. Rev. Neurol. 2017, 13, 217-231. [CrossRef]

14. Orimo, S. New development of diagnosis and treatment for Parkinson's disease. Rinsho Shinkeigaku 2017, 57, 259-273. [CrossRef] [PubMed]

15. Moors, T.E.; Hoozemans, J.J.M.; Ingrassia, A.; Beccari, T.; Parnetti, L.; Chartier-Harlin, M.-C.; Van De Berg, W.D.J. Therapeutic potential of autophagy-enhancing agents in Parkinson's disease. Mol. Neurodegener. 2017, 12, 11. [CrossRef] [PubMed]

16. Gao, G.; Chen, R.; He, M.; Li, J.; Wang, L.; Sun, T. Gold nanoclusters for Parkinson's disease treatment. Biomaterials 2019, 194, 36-46. [CrossRef] [PubMed]

17. Chen, T.; Liu, W.; Xiong, S.; Li, D.; Fang, S.; Wu, Z.; Wang, Q.; Chen, X. Nanoparticles Mediating the Sustained Puerarin Release Facilitate Improved Brain Delivery to Treat Parkinson's Disease. ACS Appl. Mater. Interfaces 2019, 11, 45276-45289. [CrossRef] [PubMed]

18. Prasuhn, J.; Brüggemann, N. Genotype-driven therapeutic developments in Parkinson's disease. Mol. Med. 2021, 27, 1-13. [CrossRef]

19. de Luzy, I.R.; Law, K.C.L.; Moriarty, N.; Hunt, C.P.J.; Durnall, J.C.; Thompson, L.H.; Nagy, A.; Parish, C.L. Human stem cells harboring a suicide gene improve the safety and standardisation of neural transplants in Parkinsonian rats. Nat. Commun. 2021, 12, 1-11. [CrossRef]

20. Hirano, S. Clinical implications for dopaminergic and functional neuroimage research in cognitive symptoms of Parkinson's disease. Mol. Med. 2021, 27, 1-9. [CrossRef]

21. Denes, A.; Thornton, P.; Rothwell, N.; Allan, S. Inflammation and brain injury: Acute cerebral ischaemia, peripheral and central inflammation. Brain, Behav. Immun. 2010, 24, 708-723. [CrossRef]

22. National Institute of Neurological Disorders and Stroke rt-PA Stroke Study Group Tissue Plasminogen Activator for Acute Ischemic Stroke. New Engl. J. Med. 1995, 333, 1581-1588. [CrossRef]

23. Mokin, M.; Snyder, K.V.; Siddiqui, A.H.; Levy, E.I.; Hopkins, L.N. Recent Endovascular Stroke Trials and Their Impact on Stroke Systems of Care. J. Am. Coll. Cardiol. 2016, 67, 2645-2655. [CrossRef] [PubMed]

24. Cook, D.J.; Nguyen, C.; Chun, H.N.; Llorente, I.L.; Chiu, A.S.; Machnicki, M.; Zarembinski, T.I.; Carmichael, S.T. Hydrogeldelivered brain-derived neurotrophic factor promotes tissue repair and recovery after stroke. Br. J. Pharmacol. 2017, 37, 1030-1045. [CrossRef]

25. Tian, X.; Fan, T.; Zhao, W.; Abbas, G.; Han, B.; Zhang, K.; Li, N.; Liu, N.; Liang, W.; Huang, H.; et al. Recent advances in the development of nanomedicines for the treatment of ischemic stroke. Bioact. Mater. 2021, 6, 2854-2869. [CrossRef] [PubMed]

26. Bernardo-Castro, S.; Albino, I.; Barrera-Sandoval, Á.; Tomatis, F.; Sousa, J.; Martins, E.; Simões, S.; Lino, M.; Ferreira, L.; Sargento-Freitas, J. Therapeutic Nanoparticles for the Different Phases of Ischemic Stroke. Life 2021, 11, 482. [CrossRef]

27. Sharma, S.; Nozohouri, S.; Vaidya, B.; Abbruscato, T. Repurposing metformin to treat age-related neurodegenerative disorders and ischemic stroke. Life Sci. 2021, 274, 119343. [CrossRef] [PubMed]

28. Davis, S.; Pennypacker, K.R. Targeting antioxidant enzyme expression as a therapeutic strategy for ischemic stroke. Neurochem. Int. 2017, 107, 23-32. [CrossRef]

29. Zhang, T.; Li, F.; Xu, Q.; Wang, Q.; Jiang, X.; Liang, Z.; Liao, H.; Kong, X.; Liu, J.; Wu, H.; et al. Ferrimagnetic Nanochains-Based Mesenchymal Stem Cell Engineering for Highly Efficient Post-Stroke Recovery. Adv. Funct. Mater. 2019, 29. [CrossRef]

30. He, L.; Huang, G.; Liu, H.; Sang, C.; Liu, X.; Chen, T. Highly bioactive zeolitic imidazolate framework-8-capped nanotherapeutics for efficient reversal of reperfusion-induced injury in ischemic stroke. Sci. Adv. 2020, 6, eaay9751. [CrossRef]

31. Alexander, B.M.; Ba, S.; Berger, M.S.; Berry, D.A.; Cavenee, W.K.; Chang, S.M.; Cloughesy, T.F.; Jiang, T.; Khasraw, M.; Liau, L.; et al. Adaptive Global Innovative Learning Environment for Glioblastoma: GBM AGILE. Clin. Cancer Res. 2018, 24, 737-743. [CrossRef] [PubMed]

32. Lee, E.; Yong, R.L.; Paddison, P.; Zhu, J. Comparison of glioblastoma (GBM) molecular classification methods. Semin. Cancer Biol. 2018, 53, 201-211. [CrossRef] [PubMed]

33. Shergalis, A.; Bankhead, A.; Luesakul, U.; Muangsin, N.; Neamati, N. Current Challenges and Opportunities in Treating Glioblastoma. Pharmacol. Rev. 2018, 70, 412-445. [CrossRef]

34. Yi, H.-G.; Jeong, Y.H.; Kim, Y.; Choi, Y.-J.; Moon, H.E.; Park, S.H.; Kang, K.S.; Bae, M.; Jang, J.; Youn, H.; et al. A bioprinted human-glioblastoma-on-a-chip for the identification of patient-specific responses to chemoradiotherapy. Nat. Biomed. Eng. 2019, 3, 509-519. [CrossRef]

35. Gomez-Roman, N.; Chalmers, A.J. Patient-specific 3D-printed glioblastomas. Nat. Biomed. Eng. 2019, 3, 498-499. [CrossRef] [PubMed] 
36. Obermeier, B.; Daneman, R.; Ransohoff, R.M. Development, maintenance and disruption of the blood-brain barrier. Nat. Med. 2013, 19, 1584-1596. [CrossRef]

37. Liu, Y.; Zou, Y.; Feng, C.; Lee, A.; Yin, J.; Chung, R.; Park, J.B.; Rizos, H.; Tao, W.; Zheng, M.; et al. Charge Conversional Biomimetic Nanocomplexes as a Multifunctional Platform for Boosting Orthotopic Glioblastoma RNAi Therapy. Nano Lett. 2020, 20, 1637-1646. [CrossRef]

38. Lam, F.C.; Morton, S.W.; Wyckoff, J.; Han, T.-L.V.; Hwang, M.K.; Maffa, A.; Balkanska-Sinclair, E.; Yaffe, M.B.; Floyd, S.R.; Hammond, P.T. Enhanced efficacy of combined temozolomide and bromodomain inhibitor therapy for gliomas using targeted nanoparticles. Nat. Commun. 2018, 9, 1-11. [CrossRef] [PubMed]

39. Zhu, M.; Sheng, Z.; Jia, Y.; Hu, D.; Liu, X.; Xiaobing, W.; Liu, C.; Wang, P.; Wang, X.; Zheng, H. Indocyanine Green-holo-Transferrin Nanoassemblies for Tumor-Targeted Dual-Modal Imaging and Photothermal Therapy of Glioma. ACS Appl. Mater. Interfaces 2017, 9, 39249-39258. [CrossRef] [PubMed]

40. Liang, K.; Li, Z.; Luo, Y.; Zhang, Q.; Yin, F.; Xu, L.; Chen, H.; Wang, H. Intelligent Nanocomposites with Intrinsic Blood-BrainBarrier Crossing Ability Designed for Highly Specific MR Imaging and Sonodynamic Therapy of Glioblastoma. Small 2020, 16, e1906985. [CrossRef] [PubMed]

41. Hussain, T.; Nguyen, Q.T. Molecular imaging for cancer diagnosis and surgery. Adv. Drug Deliv. Rev. 2014, 66, 90-100. [CrossRef]

42. Leupold, J.; Neubauer, J.; Bock, M. Spinecho und Gradientenecho. Der Radiol. 2018, 58, 769-784. [CrossRef]

43. Lohrke, J.; Frenzel, T.; Endrikat, J.; Caseiro-Alves, F.; Grist, T.M.; Law, M.; Lee, J.M.; Leiner, T.; Li, K.-C.; Nikolaou, K.; et al. 25 Years of Contrast-Enhanced MRI: Developments, Current Challenges and Future Perspectives. Adv. Ther. 2016, 33, 1-28. [CrossRef] [PubMed]

44. Shellock, F.G.; Spinazzi, A. MRI Safety Update 2008: Part 1, MRI Contrast Agents and Nephrogenic Systemic Fibrosis. Am. J. Roentgenol. 2008, 191, 1129-1139. [CrossRef]

45. Goldman, L.W. Principles of CT: Radiation Dose and Image Quality. J. Nucl. Med. Technol. 2007, 35, 213-225. [CrossRef] [PubMed]

46. Sheng, Z.; Hu, D.; Zheng, M.; Zhao, P.; Liu, H.; Gao, D.; Gong, P.; Gao, G.; Zhang, P.; Ma, Y.; et al. Smart Human Serum Albumin-Indocyanine Green Nanoparticles Generated by Programmed Assembly for Dual-Modal Imaging-Guided Cancer Synergistic Phototherapy. ACS Nano 2014, 8, 12310-12322. [CrossRef] [PubMed]

47. Zhou, M.; Zhang, R.; Huang, M.; Lu, W.; Song, S.; Melancon, M.P.; Tian, M.; Liang, D.; Li, C. A Chelator-Free Multifunctional [64Cu]CuS Nanoparticle Platform for Simultaneous Micro-PET/CT Imaging and Photothermal Ablation Therapy. J. Am. Chem. Soc. 2010, 132, 15351-15358. [CrossRef] [PubMed]

48. Gao, M.; Yu, F.; Lv, C.; Choo, J.; Chen, L. Fluorescent chemical probes for accurate tumor diagnosis and targeting therapy. Chem. Soc. Rev. 2017, 46, 2237-2271. [CrossRef] [PubMed]

49. James, M.L.; Gambhir, S.S. A Molecular Imaging Primer: Modalities, Imaging Agents, and Applications. Physiol. Rev. 2012, 92, 897-965. [CrossRef] [PubMed]

50. Dubreil, L.; Leroux, I.; Ledevin, M.; Schleder, C.; Lagalice, L.; Lovo, C.; Fleurisson, R.; Passemard, S.; Kilin, V.; Gerber-Lemaire, S.; et al. Multi-harmonic Imaging in the Second Near-Infrared Window of Nanoparticle-Labeled Stem Cells as a Monitoring Tool in Tissue Depth. ACS Nano 2017, 11, 6672-6681. [CrossRef] [PubMed]

51. Rompolas, P.; Deschene, E.R.; Zito, G.; Gonzalez, D.G.; Saotome, I.; Haberman, A.M.; Greco, V. Live imaging of stem cell and progeny behaviour in physiological hair-follicle regeneration. Nat. Cell Biol. 2012, 487, 496-499. [CrossRef]

52. Wolfbeis, O.S. An overview of nanoparticles commonly used in fluorescent bioimaging. Chem. Soc. Rev. 2015, 44, 4743-4768. [CrossRef] [PubMed]

53. Boddington, S.; Henning, T.D.; Sutton, E.J.; Daldrup-Link, H.E. Labeling Stem Cells with Fluorescent Dyes for non-invasive Detection with Optical Imaging. J. Vis. Exp. 2008, 10, e686. [CrossRef] [PubMed]

54. Nowotschin, S.; Hadjantonakis, A.-K. Photomodulatable fluorescent proteins for imaging cell dynamics and cell fate. Organogenesis 2009, 5, 217-226. [CrossRef] [PubMed]

55. Li, J.; Pu, K. Development of organic semiconducting materials for deep-tissue optical imaging, phototherapy and photoactivation. Chem. Soc. Rev. 2019, 48, 38-71. [CrossRef] [PubMed]

56. Antoch, G.; Bockisch, A. Combined PET/MRI: A new dimension in whole-body oncology imaging? Eur. J. Nucl. Med. Mol. Imaging 2009, 36, 113-120. [CrossRef] [PubMed]

57. Chen, T.-W.; Wardill, T.; Sun, Y.; Pulver, S.; Renninger, S.; Baohan, A.; Schreiter, E.; Kerr, R.A.; Orger, M.B.; Jayaraman, V.; et al. Ultrasensitive fluorescent proteins for imaging neuronal activity. Nat. Cell Biol. 2013, 499, 295-300. [CrossRef]

58. Opie, L.H.; Hesse, B. Radionuclide tracers in the evaluation of resting myocardial ischaemia and viability. Eur. J. Nucl. Med. 1997, 24, 1183-1193.

59. Weber, J.; Beard, P.C.; Bohndiek, S. Contrast agents for molecular photoacoustic imaging. Nat. Methods 2016, 13, 639-650. [CrossRef]

60. Kim, J.-W.; Galanzha, E.I.; Shashkov, E.V.; Moon, H.-M.; Zharov, V.P. Golden carbon nanotubes as multimodal photoacoustic and photothermal high-contrast molecular agents. Nat. Nanotechnol. 2009, 4, 688-694. [CrossRef]

61. Wilson, K.E.; Homan, K.; Emelianov, S. Biomedical photoacoustics beyond thermal expansion using triggered nanodroplet vaporization for contrast-enhanced imaging. Nat. Commun. 2012, 3, 618. [CrossRef]

62. Liu, Y.; Bhattarai, P.; Dai, Z.; Chen, X. Photothermal therapy and photoacoustic imaging via nanotheranostics in fighting cancer. Chem. Soc. Rev. 2019, 48, 2053-2108. [CrossRef] 
63. Block, J.; Berkoff, D.J.; Miller, L. Clinical utility of ultrasound guidance for intra-articular knee injections: A review. Clin. Interv. Aging 2012, 7, 89-95. [CrossRef]

64. Schoennagel, B.P.; Yamamura, J.; Kording, F.; Fischer, R.; Bannas, P.; Adam, G.; Kooijman, H.; Ruprecht, C.; Fehrs, K.; De Sousa, M.T. Fetal dynamic phase-contrast MR angiography using ultrasound gating and comparison with Doppler ultrasound measurements. Eur. Radiol. 2019, 29, 4169-4176. [CrossRef]

65. Yang, X.; Xu, J.; Sun, J.; Yin, L.; Guo, R.; Yan, Z. Clinical value of color Doppler ultrasound combined with serum tumor markers for the diagnosis of medullary thyroid carcinoma. Oncol. Lett. 2021, 22, 1-9. [CrossRef]

66. Lee, D.-E.; Koo, H.; Sun, I.-C.; Ryu, J.H.; Kim, K.; Kwon, I.C. Multifunctional nanoparticles for multimodal imaging and theragnosis. Chem. Soc. Rev. 2012, 41, 2656-2672. [CrossRef]

67. Lee, J.-H.; Huh, Y.-M.; Jun, Y.-W.; Seo, J.-W.; Jang, J.-T.; Song, H.-T.; Kim, S.; Cho, E.-J.; Yoon, H.-G.Y.; Suh, J.-S.; et al. Artificially engineered magnetic nanoparticles for ultra-sensitive molecular imaging. Nat. Med. 2007, 13, 95-99. [CrossRef]

68. Preul, M.C.; Caramanos, Z.; Collins, D.L.; Villemure, J.-G.; Leblanc, R.; Olivier, A.; Pokrupa, R.; Arnold, D.L. Accurate, noninvasive diagnosis of human brain tumors by using proton magnetic resonance spectroscopy. Nat. Med. 1996, 2, 323-325. [CrossRef]

69. Gleich, B.; Weizenecker, J. Tomographic imaging using the nonlinear response of magnetic particles. Nat. Cell Biol. 2005, 435, 1214-1217. [CrossRef]

70. Kyle, S.; Saha, S. Nanotechnology for the Detection and Therapy of Stroke. Adv. Healthc. Mater. 2014, 3, 1703-1720. [CrossRef]

71. Godin, B.; Sakamoto, J.H.; Serda, R.E.; Grattoni, A.; Bouamrani, A.; Ferrari, M. Emerging applications of nanomedicine for the diagnosis and treatment of cardiovascular diseases. Trends Pharmacol. Sci. 2010, 31, 199-205. [CrossRef] [PubMed]

72. Bhaskar, S.; Tian, F.; Stoeger, T.; Kreyling, W.; de la Fuente, J.M.; Grazú, V.; Borm, P.; Estrada, G.; Ntziachristos, V.; Razansky, D. Multifunctional Nanocarriers for diagnostics, drug delivery and targeted treatment across blood-brain barrier: Perspectives on tracking and neuroimaging. Part. Fibre Toxicol. 2010, 7, 3. [CrossRef] [PubMed]

73. Lockman, P.; Mumper, R.J.; Khan, M.; Allen, D.D. Nanoparticle Technology for Drug Delivery Across the Blood-Brain Barrier. Drug Dev. Ind. Pharm. 2002, 28, 1-13. [CrossRef]

74. Olivier, J.-C. Drug transport to brain with targeted nanoparticles. NeuroRx 2005, 2, 108-119. [CrossRef] [PubMed]

75. Teleanu, D.M.; Chircov, C.; Grumezescu, A.M.; Volceanov, A.; Teleanu, R.I. Contrast Agents Delivery: An Up-to-Date Review of Nanodiagnostics in Neuroimaging. Nanomaterials 2019, 9, 542. [CrossRef] [PubMed]

76. Wang, T.-W.; Rubio, N.; Kafa, H.; Venturelli, E.; Fabbro, C.; Menard-Moyon, C.; Da Ros, T.; Sosabowski, J.K.; Lawson, A.D.; Robinson, M.K.; et al. Kinetics of functionalised carbon nanotube distribution in mouse brain after systemic injection: Spatial to ultra-structural analyses. J. Control. Release 2016, 224, 22-32. [CrossRef] [PubMed]

77. Wang, J.; Ni, D.; Shen, Z.; Ren, Y.; Liu, Y.; Fan, W.; Wu, Y.; Zhang, G.; Zhang, H.; Wu, R.; et al. Exogenous Amino Acid-Loaded Nanovehicles: Stepping across Endogenous Magnetic Resonance Spectroscopy. Adv. Healthc. Mater. 2018, 7, e1800317. [CrossRef]

78. Gallo, J.; Kamaly, N.; Lavdas, I.; Stevens, E.; Nguyen, Q.-D.; Wylezinska-Arridge, M.; Aboagye, E.O.; Long, N.J. CXCR4-Targeted and MMP-Responsive Iron Oxide Nanoparticles for Enhanced Magnetic Resonance Imaging. Angew. Chem. Int. Ed. 2014, 53, 9550-9554. [CrossRef]

79. Wu, B.; Deng, K.; Lu, S.-T.; Zhang, C.-J.; Ao, Y.-W.; Wang, H.; Mei, H.; Wang, C.-X.; Xu, H.; Hu, B.; et al. Reduction-active Fe3O4-loaded micelles with aggregation- enhanced MRI contrast for differential diagnosis of Neroglioma. Biomaterials 2021, 268, 120531. [CrossRef]

80. Hou, W.; Jiang, Y.; Xie, G.; Zhao, L.; Zhao, F.; Zhang, X.; Sun, S.-K.; Yu, C.; Pan, J. Biocompatible BSA-MnO2 nanoparticles for in vivo timely permeability imaging of blood-brain barrier and prediction of hemorrhage transformation in acute ischemic stroke. Nanoscale 2021, 13, 8531-8542. [CrossRef] [PubMed]

81. Hartman, R.K.; Hallam, K.A.; Donnelly, E.M.; Emelianov, S. Photoacoustic imaging of gold nanorods in the brain delivered via microbubble-assisted focused ultrasound: A tool for in vivo molecular neuroimaging. Laser Phys. Lett. 2019, 16, 025603. [CrossRef] [PubMed]

82. Baldrighi, M.; Trusel, M.; Tonini, R.; Giordani, S. Carbon Nanomaterials Interfacing with Neurons: An In vivo Perspective. Front. Neurosci. 2016, 10, 250. [CrossRef] [PubMed]

83. Yang, S.-T.; Guo, W.; Lin, Y.; Deng, X.-Y.; Wang, H.-F.; Sun, H.-F.; Liu, Y.-F.; Wang, X.; Wang, W.; Chen, M.; et al. Biodistribution of Pristine Single-Walled Carbon Nanotubes In Vivo. J. Phys. Chem. C 2007, 111, 17761-17764. [CrossRef]

84. Gao, W.; Wang, W.; Dong, X.; Sun, Y. Nitrogen-Doped Carbonized Polymer Dots: A Potent Scavenger and Detector Targeting Alzheimer's $\beta$-Amyloid Plaques. Small 2020, 16, e2002804. [CrossRef] [PubMed]

85. Silva, G.A. Neuroscience nanotechnology: Progress, opportunities and challenges. Nat. Rev. Neurosci. 2006, 7, 65-74. [CrossRef] [PubMed]

86. Rubio, N.; Hirvonen, L.; Chong, E.Z.; Wang, T.-W.; Bourgognon, M.; Kafa, H.; Hassan, H.A.F.M.; Al-Jamal, K.T.; McCarthy, D.; Hogstrand, C.; et al. Multiphoton luminescence imaging of chemically functionalized multi-walled carbon nanotubes in cells and solid tumors. Chem. Commun. 2015, 51, 9366-9369. [CrossRef]

87. Usinskiene, J.; Ulyte, A.; Bjørnerud, A.; Venius, J.; Katsaros, V.K.; Rynkeviciene, R.; Letautiene, S.; Norkus, D.; Suziedelis, K.; Rocka, S.; et al. Optimal differentiation of high- and low-grade glioma and metastasis: A meta-analysis of perfusion, diffusion, and spectroscopy metrics. Neuroradiology 2016, 58, 339-350. [CrossRef] [PubMed]

88. Zarifi, M.; Tzika, A.A. Proton MRS imaging in pediatric brain tumors. Pediatr. Radiol. 2016, 46, 952-962. [CrossRef] [PubMed] 
89. Kugel, H.; Heindel, W.; Ernestus, R.I.; Bunke, J.; Du Mesnil, R.; Friedmann, G. Human brain tumors: Spectral patterns detected with localized H-1 MR spectroscopy. Radiology 1992, 183, 701-709. [CrossRef] [PubMed]

90. Li, G. Nano-Inspired Biosensors for Protein Assay with Clinical Applications; Elsevier: Amsterdam, The Netherlands, 2019.

91. Tang, J.; Huang, N.; Zhang, X.; Zhou, T.; Tan, Y.; Pi, J.; Pi, L.; Cheng, S.; Zheng, H.; Cheng, Y. Aptamer-conjugated PEGylated quantum dots targeting epidermal growth factor receptor variant III for fluorescence imaging of glioma. Int. J. Nanomed. 2017, 12, 3899-3911. [CrossRef] [PubMed]

92. Tsai, Y.-C.; Vijayaraghavan, P.; Chiang, W.-H.; Chen, H.-H.; Liu, T.-I.; Shen, M.-Y.; Omoto, A.; Kamimura, M.; Soga, K.; Chiu, H.-C. Targeted Delivery of Functionalized Upconversion Nanoparticles for Externally Triggered Photothermal/Photodynamic Therapies of Brain Glioblastoma. Theranostics 2018, 8, 1435-1448. [CrossRef] [PubMed]

93. Wu, S.; Cheng, Y.; Chen, Y.; Ju, Z.; Xue, X.; Kong, X. Effect of Fe3O4 Nanomaterial-Based MRI on the Efficacy of One-Sided Butterfly Sinus Lesions in the Nose. J. Nanosci. Nanotechnol. 2021, 21, 1307-1314. [CrossRef]

94. Huber, D.L. Synthesis, Properties, and Applications of Iron Nanoparticles. Small 2005, 1, 482-501. [CrossRef] [PubMed]

95. Wu, W.; Jiang, C.Z.; Roy, V.A.L. Designed synthesis and surface engineering strategies of magnetic iron oxide nanoparticles for biomedical applications. Nanoscale 2016, 8, 19421-19474. [CrossRef] [PubMed]

96. Ling, D.; Hyeon, T. Chemical Design of Biocompatible Iron Oxide Nanoparticles for Medical Applications. Small 2013, 9, 1450-1466. [CrossRef]

97. Wang, Y.-X.; Hussain, S.; Krestin, G. Superparamagnetic iron oxide contrast agents: Physicochemical characteristics and applications in MR imaging. Eur. Radiol. 2001, 11, 2319-2331. [CrossRef]

98. Ms, H.R.G.; Ostrom, Q.T.; Rouse, C.D.; Dowling, J.A.; de Blank, P.M.; Ba, C.A.K.; Elder, J.B.; Rosenfeld, S.S.; Selman, W.R.; Sloan, A.E.; et al. Trends in central nervous system tumor incidence relative to other common cancers in adults, adolescents, and children in the United States, 2000 to 2010. Cancer 2015, 121, 102-112. [CrossRef]

99. Young, R.M.; Jamshidi, A.; Davis, G.; Sherman, J.H. Current trends in the surgical management and treatment of adult glioblastoma. Ann. Transl. Med. 2015, 3. [CrossRef]

100. Kalpathy-Cramer, J.; Gerstner, E.R.; Emblem, K.; Andronesi, O.C.; Rosen, B. Advanced Magnetic Resonance Imaging of the Physical Processes in Human Glioblastoma. Cancer Res. 2014, 74, 4622-4637. [CrossRef]

101. Yao, J.; Hsu, C.-H.; Li, Z.; Kim, T.; Hwang, L.-P.; Lin, Y.-C.; Lin, Y.-Y. Magnetic Resonance Nano-Theranostics for Glioblastoma Multiforme. Curr. Pharm. Des. 2015, 21, 5256-5266. [CrossRef]

102. Hyder, F.; Hoque, S.M. Brain Tumor Diagnostics and Therapeutics with Superparamagnetic Ferrite Nanoparticles. Contrast Media Mol. Imaging 2017, 2017, 1-17. [CrossRef]

103. Stummer, W.; Pichlmeier, U.; Meinel, T.; Wiestler, O.D.; Zanella, F.; Reulen, H.-J. Fluorescence-guided surgery with 5aminolevulinic acid for resection of malignant glioma: A randomised controlled multicentre phase III trial. Lancet Oncol. 2006, 7, 392-401. [CrossRef] [PubMed]

104. Reichel, D.; Sagong, B.; Teh, J.; Zhang, Y.; Wagner, S.; Wang, H.; Chung, L.W.K.; Butte, P.; Black, K.L.; Yu, J.S.; et al. Near Infrared Fluorescent Nanoplatform for Targeted Intraoperative Resection and Chemotherapeutic Treatment of Glioblastoma. ACS Nano 2020, 14, 8392-8408. [CrossRef]

105. Israel, L.L.; Galstyan, A.; Holler, E.; Ljubimova, J.Y. Magnetic iron oxide nanoparticles for imaging, targeting and treatment of primary and metastatic tumors of the brain. J. Control. Release 2020, 320, 45-62. [CrossRef] [PubMed]

106. Bulte, J.W.M.; Walczak, P.; Janowski, M.; Krishnan, K.M.; Arami, H.; Halkola, A.; Gleich, B.; Rahmer, J. Quantitative “Hot-Spot" Imaging of Transplanted Stem Cells Using Superparamagnetic Tracers and Magnetic Particle Imaging. Tomography 2015, 1, 91-97. [CrossRef] [PubMed]

107. Ramalho, J.; Semelka, R.C.; Nunes, R.H.; AlObaidy, M.; Castillo, M. Gadolinium-Based Contrast Agent Accumulation and Toxicity: An Update. Am. J. Neuroradiol. 2015, 37, 1192-1198. [CrossRef]

108. Heye, A.K.; Culling, R.D.; Hernández, M.D.C.V.; Thrippleton, M.J.; Wardlaw, J.M. Assessment of blood-brain barrier disruption using dynamic contrast-enhanced MRI. A systematic review. Neuroimage Clin. 2014, 6, 262-274. [CrossRef] [PubMed]

109. Terreno, E.; Castelli, D.D.; Viale, A.; Aime, S. Challenges for Molecular Magnetic Resonance Imaging. Chem. Rev. 2010, 110, 3019-3042. [CrossRef] [PubMed]

110. Leyba, K.; Wagner, B. Gadolinium-based contrast agents. Curr. Opin. Nephrol. Hypertens. 2019, 28, 154-162. [CrossRef]

111. Ding, B.; Zheng, P.; Ma, P.; Lin, J. Manganese Oxide Nanomaterials: Synthesis, Properties, and Theranostic Applications. Adv. Mater. 2020, 32, e1905823. [CrossRef] [PubMed]

112. Silva, A.C.; Bock, N.A. Manganese-Enhanced MRI: An Exceptional Tool in Translational Neuroimaging. Schizophr. Bull. 2007, 34, 595-604. [CrossRef] [PubMed]

113. Wang, W.; Kong, Y.; Jiang, J.; Xie, Q.; Huang, Y.; Li, G.; Wu, D.; Zheng, H.; Gao, M.; Xu, S.; et al. Engineering the Protein Corona Structure on Gold Nanoclusters Enables Red-Shifted Emissions in the Second Near-infrared Window for Gastrointestinal Imaging Angew. Chem. Int. Ed. 2020, 59, 22431-22435. [CrossRef] [PubMed]

114. Cai, K.; Zhang, W.; Foda, M.F.; Li, X.; Zhang, J.; Zhong, Y.; Liang, H.; Li, H.; Han, H.; Zhai, T. Miniature Hollow Gold Nanorods with Enhanced Effect for In Vivo Photoacoustic Imaging in the NIR-II Window. Small 2020, 16, 482. [CrossRef]

115. Jia, X.; Xu, W.; Ye, Z.; Wang, Y.; Dong, Q.; Wang, E.; Li, D.; Wang, J. Functionalized Graphene@Gold Nanostar/Lipid for Pancreatic Cancer Gene and Photothermal Synergistic Therapy under Photoacoustic/Photothermal Imaging Dual-Modal Guidance. Small 2020, 16, 2003707. [CrossRef] [PubMed] 
116. Tsai, M.-F.; Chang, S.-H.G.; Cheng, F.-Y.; Shanmugam, V.; Cheng, Y.-S.; Su, C.-H.; Yeh, C.-S. Au Nanorod Design as Light-Absorber in the First and Second Biological Near-Infrared Windows for in Vivo Photothermal Therapy. ACS Nano 2013, 7, 5330-5342. [CrossRef]

117. Giljohann, D.A.; Seferos, D.S.; Daniel, W.L.; Massich, M.D.; Patel, P.C.; Mirkin, C.A. Gold Nanoparticles for Biology and Medicine. Angew. Chem. Int. Ed. 2010, 49, 3280-3294. [CrossRef]

118. Duncan, B.; Kim, C.; Rotello, V.M. Gold nanoparticle platforms as drug and biomacromolecule delivery systems. J. Control. Release 2010, 148, 122-127. [CrossRef] [PubMed]

119. Dreaden, E.C.; Alkilany, A.M.; Huang, X.; Murphy, C.J.; El-Sayed, M.A. The golden age: Gold nanoparticles for biomedicine. Chem. Soc. Rev. 2012, 41, 2740-2779. [CrossRef]

120. Zarschler, K.; Rocks, L.; Licciardello, N.; Boselli, L.; Polo, E.; Pombo-Garcia, K.; De Cola, L.; Stephan, H.; Dawson, K.A. Ultrasmall inorganic nanoparticles: State-of-the-art and perspectives for biomedical applications. Nanomed. Nanotechnol. Biol. Med. 2016, 12, 1663-1701. [CrossRef]

121. Wang, L.V.; Hu, S. Photoacoustic Tomography: In Vivo Imaging from Organelles to Organs. Science 2012, 335, 1458-1462. [CrossRef] [PubMed]

122. Bayer, C.L.; Nam, S.Y.; Chen, Y.-S.; Emelianov, S.Y. Photoacoustic signal amplification through plasmonic nanoparticle aggregation. J. Biomed. Opt. 2013, 18, 016001. [CrossRef]

123. Mallidi, S.; Joshi, P.P.; Sokolov, K.; Emelianov, S. On Sensitivity of Molecular Specific Photoacoustic Imaging Using Plasmonic Gold Nanoparticles, Proceedings of the 2009 Annual International Conference of the IEEE Engineering in Medicine and Biology Society, Minneapolis, MN, USA, 3-6 September 2009; Institute of Electrical and Electronics Engineers (IEEE): New York, NY, USA, 2009; Volume 2009, pp. 6338-6340.

124. Xu, C.; Tung, G.A.; Sun, S. Size and Concentration Effect of Gold Nanoparticles on X-ray Attenuation As Measured on Computed Tomography. Chem. Mater. 2008, 20, 4167-4169. [CrossRef] [PubMed]

125. Tomitaka, A.; Arami, H.; Raymond, A.; Yndart, A.; Kaushik, A.; Jayant, R.D.; Takemura, Y.; Cai, Y.; Toborek, M.; Nair, M. Development of magneto-plasmonic nanoparticles for multimodal image-guided therapy to the brain. Nanoscale 2017, 9, 764-773. [CrossRef] [PubMed]

126. Konofagou, E.E. Optimization of the Ultrasound-Induced Blood-Brain Barrier Opening. Theranostics 2012, 2, 1223-1237. [CrossRef] [PubMed]

127. Meng, Y.; Suppiah, S.; Surendrakumar, S.; Bigioni, L.; Lipsman, N. Low-Intensity MR-Guided Focused Ultrasound Mediated Disruption of the Blood-Brain Barrier for Intracranial Metastatic Diseases. Front. Oncol. 2018, 8, 338. [CrossRef] [PubMed]

128. Kircher, M.F.; De La Zerda, A.; Jokerst, J.V.; Zavaleta, C.; Kempen, P.; Mittra, E.; Pitter, K.; Huang, R.; Campos, C.; Habte, F.; et al. A brain tumor molecular imaging strategy using a new triple-modality MRI-photoacoustic-Raman nanoparticle. Nat. Med. 2012, 18, 829-834. [CrossRef] [PubMed]

129. Miao, Y.; Gu, C.; Zhu, Y.; Yu, B.; Shen, Y.; Cong, H. Recent Progress in Fluorescence Imaging of the Near-Infrared II Window. ChemBioChem 2018, 19, 2522-2541. [CrossRef] [PubMed]

130. Xu, Y.; Ren, F.; Liu, H.; Zhang, H.; Han, Y.; Liu, Z.; Wang, W.; Sun, Q.; Zhao, C.; Li, Z. Cholesterol-Modified Black Phosphorus Nanospheres for the First NIR-II Fluorescence Bioimaging. ACS Appl. Mater. Interfaces 2019, 11, 21399-21407. [CrossRef]

131. Wang, F.; Wan, H.; Ma, Z.; Zhong, Y.; Sun, Q.; Tian, Y.; Qu, L.; Du, H.; Zhang, M.; Li, L.; et al. Light-sheet microscopy in the near-infrared II window. Nat. Methods 2019, 16, 545-552. [CrossRef] [PubMed]

132. Li, Y.; Li, X.; Xue, Z.; Jiang, M.; Zeng, S.; Hao, J. Second near-infrared emissive lanthanide complex for fast renal-clearable in vivo optical bioimaging and tiny tumor detection. Biomaterials 2018, 169, 35-44. [CrossRef] [PubMed]

133. Wang, X.; Hu, H.; Zhang, H.; Li, C.; An, B.; Dai, J. Single ultrasmall Mn2+-doped NaNdF4 nanocrystals as multimodal nanoprobes for magnetic resonance and second near-infrared fluorescence imaging. Nano Res. 2018, 11, 1069-1081. [CrossRef]

134. Liu, Z.; Ren, F.; Zhang, H.; Yuan, Q.; Jiang, Z.; Liu, H.; Sun, Q.; Li, Z. Boosting often overlooked long wavelength emissions of rare-earth nanoparticles for NIR-II fluorescence imaging of orthotopic glioblastoma. Biomaterials 2019, 219, 119364. [CrossRef] [PubMed]

135. Zhu, H.; Cao, X.; Cai, X.; Tian, Y.; Wang, D.; Qi, J.; Teng, Z.; Lu, G.; Ni, Q.; Wang, S.; et al. Pifithrin- $\mu$ incorporated in gold nanoparticle amplifies pro-apoptotic unfolded protein response cascades to potentiate synergistic glioblastoma therapy. Biomaterials 2020, 232, 119677. [CrossRef] [PubMed]

136. Bao, Q.; Hu, P.; Xu, Y.; Cheng, T.; Wei, C.; Pan, L.; Shi, J. Simultaneous Blood-Brain Barrier Crossing and Protection for Stroke Treatment Based on Edaravone-Loaded Ceria Nanoparticles. ACS Nano 2018, 12, 6794-6805. [CrossRef] [PubMed]

137. Yan, R.; Sun, S.; Yang, J.; Long, W.; Wang, J.; Mu, X.; Li, Q.; Hao, W.; Zhang, S.; Liu, H.; et al. Nanozyme-Based Bandage with Single-Atom Catalysis for Brain Trauma. ACS Nano 2019, 13, 11552-11560. [CrossRef] [PubMed] 